
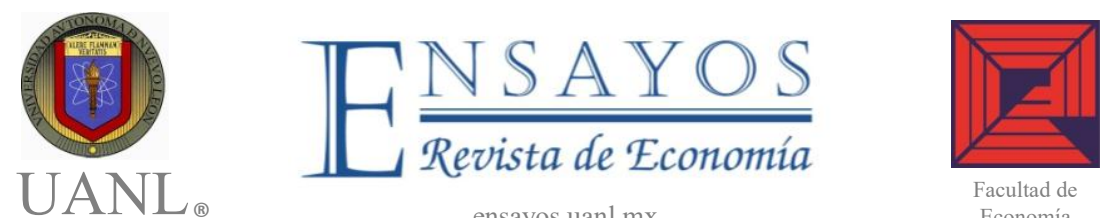

Facultad de

ensayos.uanl.mx

Economía

UNIVERSIDAD AUTÓNOMA DE NUEVO LEÓN $\square$ FACULTAD DE ECONOMIA $\square$ CENTRO DE INVESTIGACIONES ECONÓMICAS

\title{
Fiscal Institutions and the Size and Inter-Regional Distribution of Public Redistribution
}

\section{Instituciones Fiscales y el Tamaño y Distribución Inter-Regional de la Redistribución Pública}

\section{Raúl Alberto Ponce Rodríguez Juan Medina Guirado}

\begin{tabular}{|c|c|}
\hline information & Abstract \\
\hline $\begin{array}{l}\text { Accepted: } \\
20 \text { December } 2017\end{array}$ & $\begin{array}{l}\text { Fiscal institutions, which are responsible for the } \\
\text { delegation of tax and spending powers among } \\
\text { different tiers of governments, are important } \\
\text { determinants of the size and efficiency of public }\end{array}$ \\
\hline $\begin{array}{l}\text { Keywords: } \\
\text { Redistribution; Inter- } \\
\text { regional externalities; } \\
\text { Federalism; Structure } \\
\text { and scope of } \\
\text { government }\end{array}$ & $\begin{array}{l}\text { comparative analysis of the impact of fiscal } \\
\text { decentralization vis-à-vis tax revenue sharing on } \\
\text { the government's effort to redistribute income. } \\
\text { The main findings are: first, the size of the } \\
\text { national budget for public redistribution is the } \\
\text { same under fiscal decentralization and tax } \\
\text { revenue sharing. Second, different fiscal } \\
\text { institutions lead to different regional distributions } \\
\text { of public transfers. Third, when choosing between } \\
\text { decentralization and tax revenue sharing, there is } \\
\text { a tradeoff between the efficiency and the regional } \\
\text { effort of the government to redistribute income. }\end{array}$ \\
\hline
\end{tabular}

* Universidad Autónoma de Ciudad Juárez, Instituto de Ciencias Sociales y Administración, Heroico Colegio Militar y Av. Universidad No. 3775, Zona Chamizal, 32310, Ciudad Juárez, Chihuahua, México. Tel: 52-656-688-3837. rponce@uacj.mx

${ }^{* *}$ Universidad Autónoma de Ciudad Juárez, Instituto de Ciencias Sociales y Administración: juan.medina@uacj.mx 


\begin{tabular}{|c|c|}
\hline $\begin{array}{l}\text { Información del } \\
\text { artículo }\end{array}$ & Resumen \\
\hline $\begin{array}{l}\text { Recibido: } \\
14 \text { octubre } 2016 \\
\\
\text { Aceptado } \\
20 \text { diciembre } 2017\end{array}$ & $\begin{array}{l}\text { Las instituciones fiscales, que determinan la } \\
\text { responsabilidad del diseño de impuestos y gasto } \\
\text { entre los diferentes niveles de gobierno, son } \\
\text { importantes determinantes del tamaño y eficiencia }\end{array}$ \\
\hline $\begin{array}{l}\text { Clasificación JEL: } \\
\text { H72; H23; H1 } \\
\text { Palabras Clave: } \\
\text { Redistribución; } \\
\text { Externalidades inter- } \\
\text { regionales; } \\
\text { Federalismo; Estructura } \\
\text { y alcance del gobierno }\end{array}$ & $\begin{array}{l}\text { de la redistribución pública. En este artículo, se } \\
\text { desarrolla un análisis comparativo del impacto en } \\
\text { el esfuerzo del gobierno por redistribuir el } \\
\text { ingreso, entre la política de descentralización y la } \\
\text { de compartir el ingreso fiscal. Los principales } \\
\text { resultados son: primero, el tamaño del } \\
\text { presupuesto en redistribución es el mismo para } \\
\text { una economía con descentralización y en la que se } \\
\text { comparte el ingreso fiscal. Segundo, las } \\
\text { instituciones fiscales implican una asignación } \\
\text { diferente en la distribución regional de } \\
\text { transferencias públicas. Tercero, al escoger entre } \\
\text { descentralización y compartir el ingreso fiscal, se } \\
\text { observa un intercambio entre la eficiencia y la } \\
\text { distribución regional de las transferencias } \\
\text { públicas. }\end{array}$ \\
\hline
\end{tabular}

\section{Introduction}

For an economy with multiple tiers of government, misallocations of tax and spending policies might arise due to coordination failures among different levels of government. In particular, it is well known that a problem of tax coordination could induce vertical (see Keen 1998 and Wilson 1999) and horizontal tax externalities (see Devereuxa et al 2007, among others). Uncoordinated tax policies lead to horizontal fiscal externalities when subnational governments do not recognize that their tax policies affect the tax base of neighborhood districts. This, in turn, could induce state and local governments to overestimate the marginal cost of public funds leading to sub-optimal levels of state and local taxation and spending (see Wilson, 1999). Coordination failures also lead to vertical fiscal externalities because the central government does not take into account how its tax policies affect sub-national tax bases and state and local governments also do not take into account how local taxes affect the tax base of the central government. In this case, all levels of government would underestimate the marginal costs of public funds associated with raising tax revenue leading to high taxation and spending (see Johnson 1988, Boadway and Keen 1996). 
Several solutions have been explored to solve the problem of coordination failures for economies with multi-level governments: one possibility is to centralize tax and spending decisions. However, fiscal centralization could actually reduce the national social welfare because the central government might be less efficient than state or local governments in differentiating local taxes and spending according to the inter-regional heterogeneity of preferences (see Oates 1972, Ponce et al 2012). Another possibility is to centralize tax policies but decentralize spending decisions. ${ }^{1}$ In fact, several countries in the world use some form of tax revenue sharing, a policy that seeks to coordinate tax policies from sub-national governments and the central government, to avoid the negative effects associated with failures of coordination in a federation (see Rao 2007, Kochi and Ponce 2016).

Mexico is one of the countries that have adopted some form of tax revenue sharing as a way to coordinate tax policies from the central and state (same as above) governments. In the particular case of Mexico, the central and state governments signed an agreement to coordinate tax policies in which the central government collects tax revenue that is later distributed among different levels of governments. ${ }^{2}$

Although there is a large amount of literature that studies the relative merits of fiscal decentralization versus centralization (see Martinez-Vazquez et al 2015 among many others). To the best of our knowledge, there has been little research on the comparative advantages and disadvantages of adopting different fiscal institutions such as fiscal decentralization (in which tax and spending powers are given to sub-national governments) vis-à-vis a tax revenue sharing agreement in which taxation powers are delegated to the central government and (some) spending powers remain at the state level. Since the choice of fiscal institutions affects the provision of local public goods, the effort of the government to redistribute income, fight poverty, and provide important programs such as education and health services that are vital for the citizens' well-being, it is relevant from a policy making point of view, to have a better understanding of the advantages and shortcomings of these two fiscal institutions.

In this paper we seek to fill in this gap of the literature by developing a comparative analysis of the size and inter-regional distribution of public transfers that would arise under two fiscal institutions: fiscal decentralization

\footnotetext{
${ }^{1}$ This fiscal institution also has many critics, who argue that such arrangement reduces local accountability and impair the representation of the household's preferences into local policy (see Martinez-Vazquez et al 2015).

${ }^{2}$ The law of fiscal coordination in México was first implemented in 1978. The objective of this law is to coordinate the fiscal system in the Mexican federation to establish the participations of federal income to be allocated to Mexican state governments and municipalities. See http://www.diputados.gob.mx/LeyesBiblio/pdf/31_180716.pdf.
} 
versus a tax revenue sharing agreement that seeks to coordinate tax policy among state governments. To be more precise, in this paper we study the optimal allocation of public transfers for an economy that is fiscally decentralized (state governments have full command in deciding the levels of taxation and spending). We also, study the optimal allocation of public transfers for a tax revenue sharing economy: in this economy, state governments and the central government are committed to let the central government design the tax policy. After tax revenue is collected from a given tax base, state governments receive a share of the tax revenue through a formula. We then compare the size and inter-regional distribution of public transfers under these two fiscal institutions.

To do so, we develop several models in which governments are controlled by benevolent social planners that design tax and spending policies to maximize social welfare. In our analysis we distinguish two cases of interest: first, an economy in which local redistribution spending does not show spillovers. Second, an economy in which public spending leads to inter-regional spillovers. The main findings of our analysis are: first, surprisingly, that the effort to redistribute income is the same under fiscal decentralization and tax revenue sharing (that is to say, the nationwide budget for public redistribution is the same for both types of fiscal institutions). This finding is robust and it is observed in economies with and without regional spillovers from public redistribution. Second, the choice of fiscal institutions, decentralization vis-àvis tax revenue sharing, leads to differences in the public transfers' regional allocation. We identify conditions in which the size of public transfers in key districts under fiscal decentralization is higher (lower) than those under tax revenue sharing.

Third, in choosing between decentralization and tax revenue sharing as fiscal institutions, there is a tradeoff between the efficiency in the allocation of resources and the inter-regional degree of government effort to redistribute income. This tradeoff could have important implications on regional and national efficacy of the government's effort to redistribute income. In particular, our findings suggest that if there is a higher (lower) proportion of low income households in some key districts (relative to the proportion of low income households in some other districts) then the government's redistributive program is more (less) effective in redistributing welfare to the poor under a fiscally decentralized economy relative to the social welfare allotted in a centralized economy with a tax revenue sharing policy.

The rest of the paper is structured as follows: section 2 considers our models of fiscal decentralization and tax revenue sharing for an economy in which there is no spillovers. Section 3 considers the case in which public redistribution shows spillovers. Section 4 includes a comparative social analysis of the choice between decentralization and tax revenue sharing. 
Section 5 includes a calibration exercise of the model focusing on the interregional allocation of resources devoted for redistribution. Section 6 concludes with a discussion of the results and the implications for policy design.

\section{Fiscal Decentralization Versus Tax Coordination in Public Redistribution}

In the analysis that follows a comparative analysis is developed of the government's effort to reduce the inequality in income distribution under two different institutional frameworks. First, we consider a government with fiscal decentralization in which policies are uncoordinated (see section 2.1). Second, we analyze government in which there is coordinated agreement on tax policy (see section 2.2). As mentioned before, in this paper we consider tax revenue sharing as an agreement between the central and sub-national governments that seeks to coordinate their tax policies. This kind of agreement has empirical support since countries such as Mexico, India and Pakistan (see Rao 2007) use some form of tax revenue sharing. In the particular case of México, the central and subnational governments signed an agreement to coordinate tax policies in which the central government collects tax revenue that is shared among different levels of governments. ${ }^{3}$

\subsection{Income Taxation and Redistribution under Fiscal Decentralization (Uncoordinated Tax Policies)}

In this economy there are two districts $i=1,2$ and each district has a population size of $N^{i} \forall i$. Households have indirect preferences given by $v^{i}\left(w^{i}, \tau^{i}, T^{i}\right)=\alpha^{i}\left\{\ln \left(w^{i}\left(1-\tau^{i}\right)\right)+\ln \left(T^{i}\right)\right\}$ where $\alpha^{i}>0$ is a parameter measuring the intensity of preferences of a household with a competitive wage $w^{i}, \tau^{i}$ is a proportional income tax and $T^{i}$ is a per household public transfer. $^{4}$ In this economy there is heterogeneity in the household's preferences and wages. In particular, wage heterogeneity is characterized by

\footnotetext{
${ }^{3}$ By setting the same tax rate among different districts of a country, horizontal fiscal tax externalities are avoided. If policy decisions are determined by the central government then this tax agreement could also avoid vertical tax externalities because the higher tier of government can take into account how taxes affect the tax bases of subnational governments.

${ }^{4}$ Following much of the literature in public economics we assume an indirect utility function (instead of a direct utility function). This approach has the advantage of simplifying the mathematical analysis.
} 
the density $h^{i}\left(w^{i}\right): \int_{\underline{w}^{i}}^{\bar{w}^{i}} h^{i}\left(w^{i}\right) d w^{i}=N^{i} /\left(N^{i}+N^{-i}\right)$ where $\underline{w}^{i}=\min \left(w^{i}\right)$ and $\bar{w}^{i}=\max \left(w^{i}\right) \forall i .^{5}$

In this economy, the local government in each district sets an income tax $\tau^{i}$ and a per household public transfer $T^{i}$ to maximize the social welfare of residents of the district $\Psi^{i}=\int_{\underline{w}^{i}}^{\bar{w}^{i}} h^{i}\left(w^{i}\right) \Omega_{L}^{i} v^{i}\left(w^{i}, \tau^{i}, T^{i}\right) d w^{i}$ where $\Omega_{L}^{i}>0$ is the weight that the local social planner assigns for the well-being of a household with wage $w^{i}$. The public budget constraint of the local government in district $i$ is given by $B^{i}=\tau^{i} \int_{\underline{w}^{i}}^{\bar{w}^{i}} h^{i}\left(w^{i}\right) w^{i} d w^{i}$ where $B^{i}$ is the budget of the local government. Formally, the problem of the local government in each district is:

$$
\begin{gathered}
\operatorname{Max}_{\left\{\tau^{i}, T^{i}\right\}} \quad \Psi^{i}=\int_{\underline{w}^{i}}^{\bar{w}^{i}} h^{i}\left(w^{i}\right) \Omega_{L}^{i} v^{i}\left(w^{i}, \tau^{i}, T^{i}\right) d w^{i} \\
\text { s.t: } \quad B^{i}=\tau^{i} \int_{\underline{w}^{i}}^{\bar{w}^{i}} h^{i}\left(w^{i}\right) w^{i} d w^{i}
\end{gathered}
$$

Next, proposition 1 characterizes the equilibrium levels of local taxation and spending for a fiscally decentralized economy. ${ }^{6}$

Proposition 1. The set of optimal local taxes $\tau_{D}^{* i} \forall i=1,2$ and the size of public redistribution $T_{D}^{* i} \forall i$ for a government with fiscal decentralization and uncoordinated subnational tax policies are:

$$
T_{D}^{* i}=\frac{1}{2} \int_{\underline{w}^{i}}^{\bar{w}^{i}} h^{i}\left(w^{i}\right) w^{i} d w^{i} \quad \forall i=1,2
$$

\footnotetext{
${ }^{5}$ Moreover there is also preference heterogeneity which means that for each household with wage $w^{i} \in\left[\underline{w}^{i}, \bar{w}^{i}\right]$ corresponds a distribution of preferences $\alpha^{i} \in\left[\underline{\alpha}^{i}, \bar{\alpha}^{i}\right]$.

${ }^{6}$ Our paper considers a general equilibrium model. To see this, note that we consider the indirect utility of households $v^{i}\left(w^{i}, \tau^{i}, T^{i}\right)$ with an endowment or "wage" density $h^{i}\left(w^{i}\right)>0: \int_{\underline{w}^{i}}^{\bar{w}^{i}} h^{i}\left(w^{i}\right) d w^{i}$, therefore households are in their Marshallian demand function, say $x^{* i}\left(w^{i}, \tau^{i}, T^{i}\right)$, which is the utility maximizing choice of the household subject to the household's constraint. Therefore aggregate demand is $\int_{\underline{w}^{i}}^{\bar{w}^{i}} h^{i}\left(w^{i}\right) x^{* i}\left(w^{i}, \tau^{i}, T^{i}\right) d w^{i} \forall i$. In our model the aggregate supply the good is determined by $\int_{\underline{w}^{i}}^{\bar{w}^{i}} h^{i}\left(w^{i}\right) w^{i} d w^{i} \forall i$. The market clearing condition in each region is $\int_{\underline{w}^{i}}^{\bar{w}^{i}} h^{i}\left(w^{i}\right) x^{* i}\left(w^{i}, \tau^{i}, T^{i}\right) d w^{i}=\int_{\underline{w}^{i}}^{\bar{w}^{i}} h^{i}\left(w^{i}\right) w^{i} d w^{i} \forall i$.
} 


$$
\tau_{D}^{* i}=1-\frac{\int_{\underline{w}^{i}}^{\bar{w}^{i}} h^{i}\left(w^{i}\right) \Omega_{L}^{i} \alpha^{i} d w^{i}}{\theta^{* i} \int_{\underline{w}^{i}}^{\bar{w}^{i}} h^{i}\left(w^{i}\right) w^{i} d w^{i}} \quad \forall i=1,2
$$

Where $\theta^{* i}$ are the local social marginal benefits from redistribution in district $i$, and the national budget on public redistribution is

$$
B_{D}^{* i}=\sum_{\forall i=1,2} T_{D}^{* i}=\frac{1}{2} \sum_{\forall i=1,2} \int_{\underline{w}^{i}}^{\bar{w}^{i}} h^{i}\left(w^{i}\right) w^{i} d w^{i} \quad \forall i=1,2
$$

\section{Proof.}

The problem of tax and redistribution design for a subnational government in district $i=1,2$ can be characterized by the following Lagrangian

$$
\begin{aligned}
\delta^{i}\left(\tau_{D}^{i}, T_{D}^{i}, \theta^{i}\right)= & \int_{\underline{w}^{i}}^{\bar{w}^{i}} h^{i}\left(w^{i}\right) \Omega_{L}^{i} v^{i}\left(w^{i}, \tau^{i}, T^{i}\right) d w^{i} \\
& +\theta^{i}\left[\tau^{i} \int_{\underline{w}^{i}}^{\bar{w}^{i}} h^{i}\left(w^{i}\right) w^{i} d w^{i}-T^{i}\right]
\end{aligned}
$$

In (6) $\theta^{i}$ is a Lagrange multiplier. The first order conditions are:

$$
\begin{array}{cc}
\frac{\partial \delta^{i}}{\partial \tau_{D}^{* i}}=\left(\frac{-1}{1-\tau_{D}^{* i}}\right) \int_{\underline{w}^{i}}^{\bar{w}^{i}} h^{i}\left(w^{i}\right) \Omega_{L}^{i} \alpha^{i} d w^{i}+\theta^{* i} \int_{\underline{w}^{i}}^{\bar{w}^{i}} h^{i}\left(w^{i}\right) w^{i} d w^{i}=0 & \forall \tau_{D}^{* i}>0 \\
\frac{\partial \delta^{i}}{\partial T_{D}^{* i}}=\left(\frac{1}{T_{D}^{* i}}\right) \int_{\underline{w}^{i}}^{\bar{w}^{i}} h^{i}\left(w^{i}\right) \Omega_{L}^{i} \alpha^{i} d w^{i}-\theta^{* i}=0 & \forall T_{D}^{* i}>0 \\
\frac{\partial \delta^{i}}{\partial \theta^{i}}=\tau_{D}^{* i} \int_{\underline{w}^{i}}^{\bar{w}^{i}} h^{i}\left(w^{i}\right) w^{i} d w^{i}-T_{D}^{* i}=0 & \forall \theta^{i} \neq 0
\end{array}
$$

Re-arrange the first order conditions to show

$$
\tau_{D}^{* i}=1-\frac{\int_{\underline{w}^{i}}^{\bar{w}^{i}} h^{i}\left(w^{i}\right) \Omega_{L}^{i} \alpha^{i} d w^{i}}{\theta^{* i} \int_{\underline{w}^{i}}^{\bar{w}^{i}} h^{i}\left(w^{i}\right) w^{i} d w^{i}} \quad \forall i=1,2
$$


Use (8) into (9) and then into the local government's budget constraint to show

$$
T_{D}^{* i}=\frac{1}{2} \int_{\underline{w}^{i}}^{\bar{w}^{i}} h^{i}\left(w^{i}\right) w^{i} d w^{i} \quad \forall i=1,2
$$

Which implies that the national budget on public transfers in the federation, $B_{D}^{*}=\sum_{\forall i=1,2} T_{D}^{* i}$, is

$$
B_{D}^{*}=\sum_{\forall i=1,2} T_{D}^{* i}=\frac{1}{2} \sum_{\forall i=1,2} \int_{\underline{w}^{i}}^{\bar{w}^{i}} h^{i}\left(w^{i}\right) w^{i} d w^{i} \quad \forall i=1,2
$$

For an economy with fiscal decentralization, each local government recognizes the district's distribution of welfare costs associated with taxation (see condition 7) and the district's distribution of social welfare benefits from public transfers (see condition 8). At the equilibrium, $\tau_{D}^{* i} \forall i=1,2$, depends on three factors: first, the welfare costs of taxation $\int_{\underline{w}^{i}}^{\bar{w}^{i}} h^{i}\left(w^{i}\right) \Omega_{L}^{i} \alpha^{i} d w^{i}$ (an increase of the welfare cost of taxation reduces the equilibrium level of $\tau_{D}^{* i}$ ); Second, the ability of the local income tax rate to collect tax revenue which is determined by the average wage in the local district $\int_{\underline{w}^{i}}^{\bar{w}^{i}} h^{i}\left(w^{i}\right) w^{i} d w^{i}$ (increases in the average wage in the district lead to higher equilibrium levels of $\left.\tau_{D}^{* i}\right)$. Third, $\tau_{D}^{* i}$ depends positively on the district's social marginal benefits of the public transfer (which term is characterized by $\theta^{i}$ ).

In proposition 1, the equilibrium level of the per-capita transfer for a resident of district $i T_{D}^{* i}$ is characterized in condition (3) and it depends positively on the average wage of district $i$. Finally, the aggregate (nationwide) effort by sub-national governments to redistribute income under uncoordinated tax policies and fiscal decentralization depends on the nationwide average wage and it is given by $B_{D}^{*}=\sum_{\forall i=1,2} T_{D}^{* i}$ (see condition 5 of proposition 1 ).

\subsection{Redistribution under Tax Revenue Sharing (Coordinated Tax Policies)}

In this section the equilibrium level of income taxation and public redistribution with coordinated tax policies for an economy is analyzed. In this economy, state governments and the central government are committed to letting the central government design the tax policy. In particular, the central government sets a uniform $\tau_{c}$ on all districts and then allocates tax 
revenue to state governments throughout a formula for tax revenue sharing. ${ }^{7}$ Local spending is determined by the following formulas: $T_{c}^{* i}=\xi^{i} B_{c} \forall i=$ 1,2 where $B_{c}$ is the national budget devoted to redistribute income, $\xi^{i} \in$ $[0,1]: \sum_{\forall i=1,2} \xi^{i}=1$ is the share of public funds allocated to district $i$ and $T_{c}^{* i}$ is the per-capita transfer for residents of district $i{ }^{8}$

Hence, the problem of policy design for a benevolent social planner at the central government is to set the income tax $\tau_{c}$, the budget $B_{c}$ and tax revenue shares $\xi^{i}$ that finance the redistributive programs of local governments in each district $T_{c}^{* i}$ to maximize the social welfare of residents of all districts $\Psi_{c}=\sum_{\forall i=1,2} \int_{w^{i}}^{\bar{w}^{i}} h^{i}\left(w^{i}\right) \Omega_{c}^{i} v^{i}\left(w^{i}, \tau_{c}, T^{i}\right) d w^{i}$ where $\Omega_{c}^{i}>0$ is the weight that the social planner at the central government allocates for the well-being of households with wage $w^{i}$. The budget constraint of the central government is given by $B_{c}=\tau_{c} \sum_{\forall i=1,2} \int_{\underline{w}^{i}}^{\bar{w}^{i}} h^{i}\left(w^{i}\right) w^{i} d w^{i}$. Thus, the problem of policy design is:

$$
\begin{gathered}
\operatorname{Max}_{\left\{\tau_{c}, \xi^{i}, B_{c}\right\}} \quad \Psi_{c}=\sum_{\forall i=1,2} \int_{\underline{w}^{i}}^{\bar{w}^{i}} h^{i}\left(w^{i}\right) \Omega_{c}^{i} v^{i}\left(w^{i}, \tau_{c}, \xi^{i}, B_{c}\right) d w^{i} \\
\text { s.t: a) } B_{c}=\tau_{c} \sum_{\forall i=1,2} \int_{\underline{w}^{i}}^{\bar{w}^{i}} h^{i}\left(w^{i}\right) w^{i} d w^{i} \\
\text { b) } T_{c}^{* i}=\xi^{i} B_{c} \quad \forall i=1,2 \\
\text { c) } \sum_{\forall i=1,2} \xi^{i}=1
\end{gathered}
$$

Next, proposition 2 characterizes the equilibrium levels of fiscal policy under tax revenue sharing.

\footnotetext{
7 This institutional set up has empirical support since several economies allocates tax revenue from the central government to subnational governments by using a formula for tax revenue sharing, see Wilson (2007) and Rao (2007).

8 For this economy the indirect preferences for a household with wage $w^{i}$ are $v^{i}\left(w^{i}, \tau_{c}, \xi^{i}, B_{c}\right)=\alpha^{i}\left\{\ln \left(w^{i}\left(1-\tau_{c}\right)\right)+\ln \left(\xi^{i} B_{c}\right)\right\} \forall i=1,2$. This indirect utility function is obtained by substituting $\tau^{i}=\tau_{c} \forall i$ and $T_{c}^{i}=\xi^{i}$ into $v^{i}$. In the real world, one of the purposes of tax revenue sharing is to set a uniform income tax across regions $\tau^{i}=\tau_{c} \forall i$ to avoid horizontal tax externalities associated with mobile tax bases. In this paper we study this strategy because it is empirically relevant
} 
Proposition 2. The optimal tax $\tau_{c}^{*}$, shares $\xi^{* i} \forall i=1,2$, and the size of public redistribution $T_{c}^{* i} \forall i=1,2$, for an economy with tax revenue sharing are given by:

$$
\tau_{c}^{*}=1-\frac{\sum_{\forall i=1,2} \int_{\underline{w}^{i}}^{\bar{w}^{i}} h^{i}\left(w^{i}\right) \Omega_{c}^{i} \alpha^{i} d w^{i}}{\lambda_{1}^{*} \sum_{\forall i=1,2} \int_{\underline{w}^{i}}^{\bar{w}^{i}} h^{i}\left(w^{i}\right) w^{i} d w^{i}}
$$

Where $\lambda_{1}^{*}$ is the national social marginal benefit from redistribution. The formulas for tax revenue sharing are:

$$
\xi^{* i}=\frac{\int_{\underline{w}^{i}}^{\bar{w}^{i}} h^{i}\left(w^{i}\right) \Omega_{c}^{i} \alpha^{i} d w^{i}}{\sum_{\forall i=1,2} \int_{\underline{w}^{i}}^{\bar{w}^{i}} h^{i}\left(w^{i}\right) \Omega_{c}^{i} \alpha^{i} d w^{i}} \quad \forall i=1,2
$$

The implied public transfers for residents in each district are:

$$
T_{c}^{* i}=\frac{\xi^{* i}}{2} \sum_{\forall i=1,2} \int_{\underline{w}^{i}}^{\bar{w}^{i}} h^{i}\left(w^{i}\right) w^{i} d w^{i} \quad \forall i=1,2
$$

And the national effort to redistribute income in the federation, $B_{c}^{* i}=$ $\sum_{\forall i=1,2} T_{c}^{* i}$, is

$$
B_{c}^{*}=\sum_{\forall i=1,2} T_{c}^{* i}=\frac{1}{2} \sum_{\forall i=1,2} \int_{\underline{w}^{i}}^{\bar{w}^{i}} h^{i}\left(w^{i}\right) w^{i} d w^{i}
$$

\section{Proof.}

The problem of the tax revenue sharing design for an economy with coordinated tax policies in all districts can be characterized by the following Lagrangian

$$
\begin{array}{r}
\delta_{c}\left(\tau_{c}, \xi^{i}, B_{c}\right)=\sum_{\forall i=1,2} \int_{\underline{w}^{i}}^{\bar{w}^{i}} h^{i}\left(w^{i}\right) \Omega_{c}^{i} v^{i}\left(w^{i}, \tau_{c}, \xi^{i} B_{c}\right) d w^{i} \\
+\lambda_{1}\left[\tau_{c} \sum_{\forall i=1,2} \int_{\underline{w}^{i}}^{\bar{w}^{i}} h^{i}\left(w^{i}\right) w^{i} d w^{i}-B_{c}\right]+\lambda_{2}\left[1-\sum_{\forall i=1,2} \xi^{i}\right]
\end{array}
$$

Where $\lambda_{1}, \lambda_{2}$ are Lagrange multipliers. The first order conditions are: 


$$
\begin{gathered}
\frac{\partial \delta_{c}}{\partial \tau_{c}}=\left(\frac{-1}{1-\tau_{c}^{*}}\right) \sum_{\substack{\forall i=1,2 \\
=}} \int_{\underline{w}^{i}}^{\bar{w}^{i}} h^{i}\left(w^{i}\right) \Omega_{c}^{i} \alpha^{i} d w^{i}+\lambda_{1}^{*} \sum_{\forall i=1,2} \int_{\underline{w}^{i}}^{\bar{w}^{i}} h^{i}\left(w^{i}\right) w^{i} d w^{i} \\
\frac{\partial \delta_{c}}{\partial \xi^{i}}=\left(\frac{1}{\xi^{* i}}\right) \int_{\underline{w}^{i}}^{\bar{w}^{i}} h^{i}\left(w^{i}\right) \Omega_{c}^{i} \alpha^{i} d w^{i}-\lambda_{2}^{*}=0 \quad \forall \xi^{* i}>0 \quad \forall i=1,2 \\
\frac{\partial \delta_{c}}{\partial B_{c}}=\left(\frac{1}{B_{c}^{*}}\right) \sum_{\forall i=1,2} \int_{\underline{w}^{i}}^{\bar{w}^{i}} h^{i}\left(w^{i}\right) \Omega_{c}^{i} \alpha^{i} d w^{i}-\lambda_{1}^{*}=0 \quad \forall B_{c}^{*}>0 \\
\frac{\partial \delta_{c}}{\partial \lambda_{1}}=\tau_{c}^{*} \sum_{\forall i=1,2} \int_{\underline{w}^{i}}^{\bar{w}^{i}} h^{i}\left(w^{i}\right) w^{i} d w^{i}-B_{c}^{*}=0 \quad \forall \lambda_{1}^{*} \neq 0 \\
\frac{\partial \delta_{c}}{\partial \lambda_{2}}=1-\sum_{\forall i=1,2} \xi^{* i}=0 \quad \forall \lambda_{2}^{*} \neq 0
\end{gathered}
$$

Re-arrange the first order conditions to show

$$
\tau_{c}^{* i}=1-\frac{\sum_{\forall i=1,2} \int_{\underline{w}^{i}}^{\bar{w}^{i}} h^{i}\left(w^{i}\right) \Omega_{c}^{i} \alpha^{i} d w^{i}}{\lambda_{1}^{*} \sum_{\forall i=1,2} \int_{\underline{w}^{i}}^{\bar{w}^{i}} h^{i}\left(w^{i}\right) w^{i} d w^{i}}
$$

Re-arrange terms from the first order conditions to show that the formulas for tax revenue sharing are characterized as follows:

$$
\xi^{* i}=\frac{\int_{\underline{w}^{i}}^{\bar{w}^{i}} h^{i}\left(w^{i}\right) \Omega_{c}^{i} \alpha^{i} d w^{i}}{\sum_{\forall i=1,2} \int_{\underline{w}^{i}}^{\bar{w}^{i}} h^{i}\left(w^{i}\right) \Omega_{c}^{i} \alpha^{i} d w^{i}} \quad \forall i=1,2
$$

The implied public transfers for residents in each district are

$$
T_{c}^{* i}=\frac{\xi^{* i}}{2} \sum_{\forall i=1,2} \int_{\underline{w}^{i}}^{\bar{w}^{i}} h^{i}\left(w^{i}\right) w^{i} d w^{i} \quad \forall i=1,2
$$

And the national effort to redistribute income in the economy, $B_{c}^{* i}=$ $\sum_{\forall i=1,2} T_{c}^{* i}$, is 


$$
B_{c}^{*}=\sum_{\forall i=1,2} T_{c}^{* i}=\frac{1}{2} \sum_{\forall i=1,2} \int_{\underline{w}^{i}}^{\bar{w}^{i}} h^{i}\left(w^{i}\right) w^{i} d w^{i} \quad \forall i=1,2
$$

Proposition 2 characterizes the equilibrium levels of taxation and spending for local governments for an economy with tax coordination and revenue sharing. The optimal level of the income tax $\tau_{c}^{*}$ is explained by the national distribution of welfare costs from taxation (this term is $\sum_{\forall i=1,2} \int_{\underline{w}^{i}}^{\bar{w}^{i}} h^{i}\left(w^{i}\right) \Omega_{c}^{i} \alpha^{i} d w^{i}$ in condition 17), the ability of the income tax to raise tax revenue (this term is $\sum_{\forall i=1,2} \int_{\underline{w}^{i}}^{\bar{w}^{i}} h^{i}\left(w^{i}\right) w^{i} d w^{i}$ in condition 17), and the national distribution of social marginal benefits from redistribution $\lambda_{1}^{*}$. Under tax revenue sharing, optimality requires that the social marginal benefits from the funds allocated in district one must be equal to the social marginal benefits of funds allocated in district two (see condition 23). ${ }^{9}$

Moreover, the shares of funds to be allocated in district $i, \xi^{* i} \forall i=1,2$, depend only on the ratio between the distribution of the social marginal benefits from public transfers in district $i$ in relation to the national distribution of social marginal benefits from public transfers (see condition 18). ${ }^{10}$ The size of the public transfer for a resident in district $i$ depends on the share of funds to be allocated in the district, $\xi^{* i}$, and the nationwide average wage $\sum_{\forall i=1,2} \int_{\underline{w}^{i}}^{\bar{w}^{i}} h^{i}\left(w^{i}\right) w^{i} d w^{i}$.

Propositions 1 and 2 also show that the national budget devoted to redistribute income by all governments is the same in the equilibrium with fiscally uncoordinated decentralized tax policies and the equilibrium with tax coordinated policies, that is, $B_{D}^{*}=B_{c}^{*}$. However the regional distribution of per-capita transfers under fiscal decentralization is generally different to that adopted under the equilibrium with tax revenue sharing. This difference is explained by two facts: first, under fiscal decentralization, state and local governments only consider the local distribution of preferences, while under the tax revenue sharing policy, what matters is the relative local benefits from public district redistribution in relation to the national benefits. Second, optimality conditions require that, under tax revenue sharing, the local marginal benefits from public redistribution must be equalized across

\footnotetext{
${ }^{9}$ This is an optimality condition that is not required under fiscal decentralization and it affects the regional distribution of public transfers.

${ }^{10}$ Note that the formulas for revenue sharing do not depend on the relative contribution of tax revenue of each district. This has important implications on the design of formulas for tax revenue sharing because in practice most formulas take into account how local governments contribute to the general fund of tax revenue.
} 
districts while state and local governments under fiscal decentralization do not operate with this constraint.

Since the main distinction in our economy between the choice of fiscal institutions (decentralization versus tax revenue sharing) relies on the outcomes of the regional distribution in public transfers, in proposition 3, we identify conditions in which $T_{D}^{* i} \frac{\geq}{<} T_{c}^{* i} \forall i$.

Proposition 3. If $\xi^{* i} \in(0,1): \xi^{* i} \leq \frac{\int_{\underline{w}^{i}}^{\bar{w}^{i}} h^{i}\left(w^{i}\right) w^{i} d w^{i}}{\sum_{\forall i=1,2} \int_{\underline{w}^{i}}^{\bar{w}^{i}} h^{i}\left(w^{i}\right) w^{i} d w^{i}}$ then $^{l 1}$
$T_{D}^{* i} \stackrel{<}{<} T_{c}^{* i}$ and $T_{D}^{*-i} \leq T_{c}^{* i}$

Proof.

From our assumption, $\quad \xi^{* i} \leq \frac{\int_{\underline{w}^{i}}^{\bar{w}^{i}} h^{i}\left(w^{i}\right) w^{i} d w^{i}}{\sum_{\forall i=1,2} \int_{\underline{w}^{i}}^{\bar{w}^{i}} h^{i}\left(w^{i}\right) w^{i} d w^{i}} \quad$ which $\quad$ implies $\frac{\xi^{* i}}{2} \sum_{\forall i=1,2} \int_{\underline{w}^{i}}^{\bar{w}^{i}} h^{i}\left(w^{i}\right) w^{i} d w^{i} \leq \frac{1}{2} \int_{\underline{w}^{i}}^{\bar{w}^{i}} h^{i}\left(w^{i}\right) w^{i} d w^{i} . \quad$ Since $\quad T_{c}^{* i}=$ $\frac{\xi^{* i}}{2} \sum_{\forall i=1,2} \int_{\underline{w}^{i}}^{\bar{w}^{i}} h^{i}\left(w^{i}\right) w^{i} d w^{i}$ and $T_{D}^{* i}=\frac{1}{2} \int_{\underline{w}^{i}}^{\bar{w}^{i}} h^{i}\left(w^{i}\right) w^{i} d w^{i}$ it follows that $T_{D}^{* i} \underset{<}{<} T_{C}^{* i}$.

Moreover,

$\xi^{* i} \leq \frac{\int_{\underline{w^{i}}}^{\bar{w}^{i} h^{i}\left(w^{i}\right) w^{i} d w^{i}}}{\sum_{\forall i=1,2} \int_{\underline{w}^{i}}^{\bar{w}^{i}} h^{i}\left(w^{i}\right) w^{i} d w^{i}} \Rightarrow \xi^{*-i} \frac{\int_{\underline{w^{-i}}}^{\bar{w}^{-i} h^{-i}\left(w^{-i}\right) w^{-i} d w^{-i}}}{\sum_{\forall i=1,2} \int_{\underline{w}^{i}}^{\bar{w}^{i}} h^{i}\left(w^{i}\right) w^{i} d w^{i}}$ which implies $\frac{\xi^{*-i}}{2} \sum_{\forall i=1,2} \int_{\underline{w}^{i}}^{\bar{w}^{i}} h^{i}\left(w^{i}\right) w^{i} d w^{i} \geq \frac{1}{2} \int_{\underline{w}^{-i}}^{\bar{w}^{-i}} h^{-i}\left(w^{-i}\right) w^{-i} d w^{-i} \quad$ therefore $T_{D}^{*-i} \leq T_{c}^{*-i}$.

Propositions 1 to 3 show that the choice of fiscal institutions lead to differences in the regional allocation of public transfers due to the differences between decentralization and tax revenue sharing in the way that they aggregate the demands for public redistribution from their citizens. decentralization and tax revenue sharing aggregate differently the demands for public redistribution from citizens. ${ }^{12}$ Moreover, proposition 3 shows that the difference between the regional distributions of per-capita transfers under

\footnotetext{
${ }^{11}$ When convenient, we will use the notation $i,-i$ to characterize two different districts. Hence, if district $i=1$, then district $-i=2$.

12 While fiscal decentralization only takes into account the demands for public redistribution from local households, tax revenue sharing takes into account the national distribution of the household's preferences for redistribution. Hence, these fiscal institutions aggregate the household's demands differently for public redistribution.
} 
fiscal decentralization vis-à-vis tax revenue sharing depends on the relative distribution of the household's social marginal benefits from public redistribution and the distribution of income. ${ }^{13}$ In particular, if the share that allocates tax revenue in district $i, \xi^{* i}$, under tax revenue sharing is lower than the share of the average income in district $i$ in relation to the national average income, that is if $\xi^{* i}<\frac{\int_{\underline{w}^{i}}^{\bar{w}^{i}} h^{i}\left(w^{i}\right) w^{i} d w^{i}}{\sum_{\forall i=1,2} \int_{\underline{w}^{i}}^{\bar{w}^{i}} h^{i}\left(w^{i}\right) w^{i} d w^{i}}$ then $T_{D}^{* i}>T_{c}^{* i}$ and $T_{D}^{*-i}<$ $T_{c}^{*-i}$. Hence, the per-capita transfer in district $i$ (district $-i$ ) is higher (lower) under a fiscally decentralized economy relative to the transfers adopted in an economy with tax revenue sharing.

This outcome might have important implications on the regional and nationwide efficacy of the government's effort to redistribute income. In particular, this outcome suggests that if there is a higher (lower) proportion of low income households in district $i$ (relative the proportion of low income households in district $-i$ ) then the government's redistributive program could be more (less) effective in redistributing welfare to the poor under a fiscally decentralized economy relative to the social welfare achieved in a centralized economy with a tax revenue sharing policy.

\section{Inter-Regional Spillovers from Redistribution}

There is a lot of literature in economics that consider the utility of individuals are interdependent (see Bergstrom 1995 among many others). ${ }^{14}$ If preferences of a household are interdependent then an individual not only cares about his own consumption but also in the consumption of other individuals. In the context of indirect preferences, the well-being of a household not only depends on its own wage, income tax and public transfer but on another household's wage, income tax and public transfer which might be a resident of district $i$ or district $-i$. If indirect preferences are interdependent among individuals residing in different districts then public redistribution would lead to inter-regional spillovers (a possibility first analyzed by Pauly 1973). ${ }^{15}$ The interest of this paper is to analyze, precisely, the role of inter-regional spillovers that leads to coordination failures under fiscal decentralization,

\footnotetext{
${ }^{13}$ Recall that $\xi^{* i}$ is the ratio between the social marginal benefits of income of residents of district $i$ and the nationwide distribution of social marginal benefits of income.

14 Bergstrom (1995) considers that preferences are interdependent when household members display feelings such as love, envy, etc.

${ }^{15}$ An intuitive case in which inter-regional spillovers of redistribution might arise is the case in which members of a family live in different districts. Family ties would explain why preferences of households with members living in different districts are interdependent.
} 
while under the tax revenue sharing policy the effect of spillovers will be internalized. ${ }^{16,17}$

In this case, interdependent indirect preferences are given by $v^{i}\left(w^{i}, \tau^{i}, T^{i}, w^{-i}, \tau^{-i}, T^{-i}\right)=$ $\alpha^{i}\left\{\ln \left(w^{i}\left(1-\tau^{i}\right)\right)+\ln \left(T^{i}\right)+k^{-i}\left[\ln \left(w^{-i}\left(1-\tau^{-i}\right)\right)+\ln \left(T^{-i}\right)\right]\right\}$ where $k^{-i} \in(0,1)$ is a parameter measuring the extent of inter-regional spillovers explained by interdependent preferences where $w^{-i}$ is the wage of a household living in district $-i, \tau^{-i}$ is a proportional income tax in district $-i$, and $T^{-i}$ is a per household public transfer of the household in district $-i$.

For an economy with tax revenue sharing due to tax coordination, the indirect preferences for a household with wage $w^{i}$ are $v^{i}\left(w^{i}, w^{-i}, \tilde{\tau}_{c}, \tilde{\xi}^{i}, \tilde{\xi}^{-i} \tilde{B}_{c}\right)=$ $\alpha^{i}\left\{\ln \left(w^{i}\left(1-\tilde{\tau}_{c}\right)\right)+\ln \left(\tilde{\xi}^{i} \tilde{B}_{c}\right)+\right.$ $\left.+k^{-i}\left[\ln \left(w^{-i}\left(1-\tilde{\tau}_{c}\right)\right)+\ln \left(\tilde{\xi}^{-i} \tilde{B}_{c}\right)\right]\right\} \forall i$ where $\tilde{\xi}^{i}, \tilde{\xi}^{-i}$ are the shares from tax revenue to be allocated in districts $i,-i, \tilde{\tau}_{c}$ is the proportional income tax implemented under tax coordination policies, and $\tilde{B}_{c}$ is the overall budget for public redistribution. ${ }^{18}$

Oates (1972) recognized that in a fiscally decentralized economy, local governments have no incentives to internalize inter-regional spillovers from redistribution. In this case, it is simple to show that the equilibrium conditions identified by proposition 1 remain unchanged. However, for an economy with tax revenue sharing, spillovers will be internalized. Proposition 4 characterizes the equilibrium tax, $\tilde{\tau}_{c}^{*}$, shares of tax revenue, $\tilde{\xi}^{* i}$, per-capita transfers, $\tilde{T}_{c}^{* i} \forall i$, and the overall budget for public redistribution $\widetilde{B}_{C}^{*}$.

Proposition 4. The optimal tax $\tilde{\tau}_{c}^{*}$, tax revenue sharing allocations $\tilde{\xi}^{* i}$, the size of public redistribution $\tilde{T}_{c}^{* i} \forall i=1,2$, and the national budget on public redistribution, $\tilde{B}_{c}^{*}$, for an economy with tax coordinated policies and spillovers from redistribution are:

${ }^{16}$ Since the seminal work of Oates (1972) there has been a great deal of interest in literature on fiscal federalism devoted to local public goods with spillovers. This is why we are also interested in developing a comparative analysis of fiscal institutions (decentralization versus tax revenue sharing) in the context of public transfers.

${ }^{17}$ The interdependence of preferences with members of a family who live in the same district also lead to spillovers. However these externalities are contained in the district. The conclusions of the previous section remain basically unchanged. For this reason, in this section, we emphasize the analysis of inter-regional spillovers.

18 The indirect utility $v^{i}\left(w^{i}, w^{-i}, \tilde{\tau}_{c}, \tilde{\xi}^{i}, \tilde{\xi}^{-i} \widetilde{B}_{c}\right)$ is obtained by using $\tilde{T}^{i}=\tilde{\xi}^{i} \widetilde{B}_{c} \forall i$ and $\tau^{i}=\tau^{-i}=\tilde{\tau}_{c}$ in the indirect utility function. 


$$
\tilde{\tau}_{c}^{*}=1-\frac{\Phi^{i}+\Phi^{-i}}{\lambda_{1}^{*} \sum_{\forall i=1,2} \int_{\underline{w}^{i}}^{\bar{w}^{i}} h^{i}\left(w^{i}\right) w^{i} d w^{i}}
$$

Where $\Phi^{i}=\int_{\underline{w}^{i}}^{\bar{w}^{i}} h^{i}\left(w^{i}\right) \Omega_{c}^{i} \alpha^{i} d w^{i}+k^{-i} \int_{\underline{w}^{-i}}^{\bar{w}^{-i}} h^{-i}\left(w^{-i}\right) \Omega_{c}^{-i} \alpha^{-i} d w^{-i}$ is the distribution of the social marginal benefits from public transfers for residents in district $i$ and its spillovers effects in district $-i$, and a similar interpretation is given $\Phi^{-i}=\int_{\underline{w}^{-i}}^{\bar{w}^{-i}} h^{-i}\left(w^{-i}\right) \Omega_{c}^{-i} \alpha^{-i} d w^{-i}+k^{i} \int_{\underline{w}^{i}}^{\bar{w}^{i}} h^{i}\left(w^{i}\right) \Omega_{c}^{i} \alpha^{i} d w^{i}$.

The formulas for tax revenue sharing are given by:

$$
\tilde{\xi}^{* i}=\frac{\Phi^{i}}{\Phi^{i}+\Phi^{-i}} \quad \forall i,-i
$$

The implied public transfers for residents in each district are:

$$
\tilde{T}_{c}^{* i}=\frac{\tilde{\xi}^{* i}}{2} \sum_{\forall i=1,2} \int_{\underline{w}^{i}}^{\bar{w}^{i}} h^{i}\left(w^{i}\right) w^{i} d w^{i} \quad \forall i=1,2
$$

And the national budget for public redistribution $\widetilde{B}_{c}^{* i}=\sum_{\forall i=1,2} \widetilde{T}_{c}^{* i}$, is

$$
\tilde{B}_{c}^{*}=\sum_{\forall i=1,2} \tilde{T}_{c}^{* i}=\frac{1}{2} \sum_{\forall i=1,2} \int_{\underline{w}^{i}}^{\bar{w}^{i}} h^{i}\left(w^{i}\right) w^{i} d w^{i} \quad \forall i=1,2
$$

\section{Proof.}

The problem of a tax policy design and a tax revenue sharing policy design for an economy with spillovers from redistribution can be characterized by the following Lagrangian

$$
\begin{array}{r}
\tilde{\delta}_{c}\left(w^{i}, w^{-i}, \tilde{\tau}_{c}, \tilde{\xi}^{i}, \tilde{\xi}^{-i}, \tilde{B}_{c}\right) \\
=\sum_{\forall i=1,2} \int_{\underline{w}^{i}}^{\bar{w}^{i}} h^{i}\left(w^{i}\right) \Omega_{c}^{i} v^{i}\left(w^{i}, w^{-i}, \tilde{\tau}_{c}, \tilde{\xi}^{i}, \tilde{\xi}^{-i}, \tilde{B}_{c}\right) d w^{i} \\
+\tilde{\lambda}_{1}\left[\tilde{\tau}_{c} \sum_{\forall i=1,2} \int_{\underline{w}^{i}}^{\bar{w}^{i}} h^{i}\left(w^{i}\right) w^{i} d w^{i}-\tilde{B}_{c}\right]+\tilde{\lambda}_{2}\left[1-\sum_{\forall i=1,2} \tilde{\xi}^{i}\right]
\end{array}
$$


In condition (36), $\tilde{\lambda}_{1}, \tilde{\lambda}_{2}$ are Lagrange multipliers. The first order conditions are given by:

$$
\begin{aligned}
& \frac{\partial \delta_{c}}{\partial \tilde{\tau}_{c}}=\left(\frac{-1}{1-\tilde{\tau}_{c}^{*}}\right)\left\{\Phi^{i}+\Phi^{-i}\right\}+\tilde{\lambda}_{1}^{*} \sum_{\forall i=1,2} \int_{\underline{w}^{i}}^{\bar{w}^{i}} h^{i}\left(w^{i}\right) w^{i} d w^{i}=0 \quad \forall \tilde{\tau}_{c}^{*} \\
& >0
\end{aligned}
$$

Where $\Phi^{i}=\int_{\underline{w}^{i}}^{\bar{w}^{i}} h^{i}\left(w^{i}\right) \Omega_{c}^{i} \alpha^{i} d w^{i}+k^{-i} \int_{\underline{w}^{-i}}^{\bar{w}^{-i}} h^{-i}\left(w^{-i}\right) \Omega_{c}^{-i} \alpha^{-i} d w^{-i} \quad$ and $\Phi^{-i}=\int_{\underline{w}^{-i}}^{\bar{w}^{-i}} h^{-i}\left(w^{-i}\right) \Omega_{c}^{-i} \alpha^{-i} d w^{-i}+k^{i} \int_{\underline{w}^{i}}^{\bar{w}^{i}} h^{i}\left(w^{i}\right) \Omega_{c}^{i} \alpha^{i} d w^{i}$

$$
\begin{gathered}
\frac{\partial \delta_{c}}{\partial \tilde{\xi}^{i}}=\left(\frac{1}{\tilde{\xi}^{* i}}\right) \Phi^{i}-\tilde{\lambda}_{2}^{*}=0 \quad \forall \tilde{\xi}^{* i}>0 \quad \forall i \\
\frac{\partial \delta_{c}}{\partial \tilde{B}_{c}}=\left(\frac{1}{\tilde{B}_{c}^{*}}\right)\left\{\Phi^{i}+\Phi^{-i}\right\}-\tilde{\lambda}_{1}^{*}=0 \quad \forall B_{c}^{*}>0 \\
\frac{\partial \delta_{c}}{\partial \tilde{\lambda}_{1}}=\tilde{\tau}_{c}^{*} \sum_{\forall i=1,2} \int_{\underline{w}^{i}}^{\bar{w}^{i}} h^{i}\left(w^{i}\right) w^{i} d w^{i}-\tilde{B}_{c}^{*}=0 \quad \forall \tilde{\lambda}_{1}^{*} \neq 0 \\
\frac{\partial \delta_{c}}{\partial \tilde{\lambda}_{2}}=1-\sum_{\forall i=1,2} \tilde{\xi}^{* i}=0 \quad \forall \tilde{\lambda}_{2}^{*} \neq 0
\end{gathered}
$$

Re-arrange first order conditions to show

$$
\tilde{\tau}_{c}^{*}=1-\frac{\Phi^{i}+\Phi^{-i}}{\tilde{\lambda}_{1}^{*} \sum_{\forall i=1,2} \int_{\underline{w}^{i}}^{\bar{w}^{i}} h^{i}\left(w^{i}\right) w^{i} d w^{i}}
$$

Also re-arrange terms to show that the formulas for tax revenue sharing are:

$$
\tilde{\xi}^{* i}=\frac{\Phi^{i}}{\Phi^{i}+\Phi^{-i}} \quad \forall i
$$

The implied public transfers for residents in each district are:

$$
\tilde{T}_{c}^{* i}=\frac{\tilde{\xi}^{* i}}{2} \sum_{\forall i=1,2} \int_{\underline{w}^{i}}^{\bar{w}^{i}} h^{i}\left(w^{i}\right) w^{i} d w^{i} \quad \forall i
$$

Therefore, the national budget for public transfers in the government, $\tilde{B}_{c}^{*}=\sum_{\forall i=1,2} \tilde{T}_{c}^{* i}$, is 


$$
\widetilde{B}_{c}^{*}=\sum_{\forall i=1,2} \tilde{T}_{c}^{* i}=\frac{1}{2} \sum_{\forall i=1,2} \int_{\underline{w}^{i}}^{\bar{w}^{i}} h^{i}\left(w^{i}\right) w^{i} d w^{i} \quad \forall i
$$

Proposition 4 shows that the equilibrium level of the income tax $\tilde{\tau}_{c}^{*}$ is explained (see condition 42) by the distribution of direct welfare costs and the spillovers welfare costs from taxation (this is the term $\Phi^{i}+\Phi^{-i}$ in condition 42), the ability of the income tax to raise revenue (which is given by the national average wage $\left.\sum_{\forall i=1,2} \int_{\underline{w}^{i}}^{\bar{w}^{i}} h^{i}\left(w^{i}\right) w^{i} d w^{i}\right)$ and the national social marginal benefits provided by the redistributive program $\tilde{\lambda}_{1}^{*}$.

An important difference with the model of this section, relative to the model of tax revenue sharing in section 2.2, is that the share of funds to be allocated in each district $\tilde{\xi}^{* i} \forall i=1,2$ depends on the ratio between the distribution of the social marginal benefits from public transfers for residents in district $i$ and its spillovers effects in district $-i, \Phi^{i}$, in relation to the overall (direct plus the spillovers) effects of transfers in district $i$ and $-i, \Phi^{i}+\Phi^{-i}$, (see condition 43). Condition (44) also says that $\tilde{T}_{c}^{* i}$ depends on the share of funds to be allocated in district $i, \tilde{\xi}^{* i}$, and the national average wage $\sum_{\forall i=1,2} \int_{\underline{w}^{i}}^{\bar{w}^{i}} h^{i}\left(w^{i}\right) w^{i} d w^{i}$.

Proposition 4 also shows that the nationwide budget devoted to redistribute income by the government for an economy with spillovers from public redistribution is the same as the equilibrium budget for an economy with tax coordination in which redistribution does not show spillovers, that is $B_{c}^{*}=$ $\tilde{B}_{c}^{*}$. However, proposition 5, identifies conditions in which the regional distribution of tax revenue sharing, and therefore the regional allocation of per-capita transfers, for economies with tax coordination with and without spillovers are different. That is, proposition 5 identifies conditions in which the share of tax revenue allocated in district $i$ (relative district $-i$ ) is $\xi^{* i} \geq \tilde{\xi}^{* i}$ and therefore $T_{c}^{* i} \underset{<}{<} \widetilde{T}_{c}^{* i}$.

Proposition 5. If

$k^{i}\left(\int_{\underline{w}^{i}}^{\bar{w}^{i}} h^{i}\left(w^{i}\right) \Omega_{c}^{i} \alpha^{i} d w^{i}\right)^{2} \geq k^{-i}\left(\int_{\underline{w}^{-i}}^{\bar{w}^{-i}} h^{-i}\left(w^{-i}\right) \Omega_{c}^{-i} \alpha^{-i} d w^{-i}\right)^{2}$

then $\xi^{* i} \frac{\geq}{<} \tilde{\xi}^{* i}$.

\section{Proof.}

See appendix 1. 
Proposition 5 identifies conditions that explain the relative proportion of funds to be allocated in district $i$ for economies with and without spillovers from public redistribution. While spillovers from public transfers in district $i$ create the rationale for an increase in the amount of resources to be allocated in the district (because spillovers from redistribution increase the national level of social marginal benefits from public transfers in district $i$ ), the actual formula for the allocation of tax revenue in district $i, \tilde{\xi}^{* i}$, depends, not on the level of national social marginal benefits, but on the ratio between the distribution of the national social marginal benefits from public transfers for residents in district $i$ and its spillover effect in district $i, \Phi^{i}$, in relation to the overall (direct plus the spillovers) effects of transfers in district $i$ and $-i$, $\Phi^{i}+\Phi^{-i}$, (see condition 43). Simultaneously, the share of tax revenue to be allocated in district $i$ for an economy in which redistribution does not show spillovers, $\xi^{* i}$, depends only on the ratio between the distribution of the social marginal benefits from public transfers for residents in district $i$ in relation to the national social marginal benefits from public transfers in district $i$ and $-i$, (see proposition 2, condition 18). Hence, the differences between $\tilde{\xi}^{* i}$ and $\xi^{* i}$ are explained by the asymmetric regional distribution of spillovers (ingeneral $k^{i} \neq k^{-i}$ and $\left.\int_{\underline{w}^{i}}^{\bar{w}^{i}} h^{i}\left(w^{i}\right) \Omega_{c}^{i} \alpha^{i} d w^{i} \neq \int_{\underline{w}^{-i}}^{\bar{w}^{-i}} h^{-i}\left(w^{-i}\right) \Omega_{c}^{-i} \alpha^{-i} d w^{-i}\right)$. Under the condition identified in proposition 5, the tax revenue allocated in district $i$ for economies with and without spillovers from public transfers is $\xi^{* i} \frac{>}{<} \tilde{\xi}^{* i}$ which implies $T_{c}^{* i} \underset{<}{<} \widetilde{T}_{c}^{* i}$.

Next, proposition 6 compares the regional distribution of per-capita transfers between economies with tax revenue sharing and fiscal decentralization for the case in which public transfers show inter-regional spillovers.

Proposition 6. If

$\tilde{\xi}^{* i} \in(0,1): \quad \tilde{\xi}^{* i}=\frac{\Phi^{i}}{\Phi^{i}+\Phi^{-i}}>\frac{\int_{\underline{w}^{i}}^{\bar{w}^{i}} h^{i}\left(w^{i}\right) w^{i} d w^{i}}{\sum_{\forall i=1,2} \int_{\underline{w}^{i}}^{\bar{w}^{i}} h^{i}\left(w^{i}\right) w^{i} d w^{i}}$

Then

$$
T_{D}^{* i} \frac{>}{<} T_{C}^{* i} \text { and } T_{D}^{*-i} \frac{<}{>} T_{c}^{* i}
$$




\section{Proof.}

From our assumption $\tilde{\xi}^{* i}=\frac{\Phi^{i}}{\Phi^{i}+\Phi^{-i}}>\frac{\int_{\underline{w}^{i}}^{\bar{w}^{i}} h^{i}\left(w^{i}\right) w^{i} d w^{i}}{\sum \forall i=1,2 \int_{\underline{w^{i}}}^{\bar{w}^{i}} h^{i}\left(w^{i}\right) w^{i} d w^{i}}$, then $\frac{\tilde{\xi}^{* i}}{2} \sum_{\forall i=1,2} \int_{\underline{w}^{i}}^{\bar{w}^{i}} h^{i}\left(w^{i}\right) w^{i} d w^{i} \leq \frac{1}{2} \int_{\underline{w}^{i}}^{\bar{w}^{i}} h^{i}\left(w^{i}\right) w^{i} d w^{i}$.

Since $\tilde{T}_{c}^{* i}=\frac{\tilde{\xi}^{* i}}{2} \sum_{\forall i=1,2} \int_{\underline{w}^{i}}^{\bar{w}^{i}} h^{i}\left(w^{i}\right) w^{i} d w^{i}$ and $T_{D}^{* i}=\frac{1}{2} \int_{\underline{w}^{i}}^{\bar{w}^{i}} h^{i}\left(w^{i}\right) w^{i} d w^{i}$ it follows that $T_{D}^{* i} \frac{2}{<} \widetilde{T}_{c}^{* i}$.

Moreover, $\tilde{\xi}^{* i} \frac{\int_{\underline{w}^{i}}^{\bar{w}^{i}} h^{i}\left(w^{i}\right) w^{i} d w^{i}}{\sum_{\forall i=1,2} \int_{\underline{w}^{i}}^{\bar{w}^{i}} h^{i}\left(w^{i}\right) w^{i} d w^{i}} \Rightarrow \tilde{\xi}^{*-i} \geq \frac{\int_{w^{-i}}^{\bar{w}^{-i} h^{-i}\left(w^{-i}\right) w^{-i} d w^{-i}}}{\sum_{\forall i=1,2} \int_{\underline{w}^{i}}^{\bar{w}^{i}} h^{i}\left(w^{i}\right) w^{i} d w^{i}}$ which implies $\frac{\tilde{\xi}^{*-i}}{2} \sum_{\forall i=1,2} \int_{\underline{w}^{i}}^{\bar{w}^{i}} h^{i}\left(w^{i}\right) w^{i} d w^{i} \geq \frac{1}{2} \int_{\underline{w}^{-i}}^{\bar{w}^{-i}} h^{-i}\left(w^{-i}\right) w^{-i} d w^{-i}$ Therefore, $T_{D}^{*-i} \frac{<}{>} \tilde{T}_{c}^{*-i}$.

Proposition 6 shows that the difference between the distribution of per-capita transfers under fiscal decentralization and tax revenue sharing when public transfers display inter-regional spillovers depends on the relative distribution of household's preferences, the distribution of spillovers from public redistribution, and the distribution of income. If the formula that allocates tax revenue in district $i, \tilde{\xi}^{* i}$, under an agreement of tax revenue sharing is lower than the ratio between the average wage of residents of district $i$ and the national average wage, that is if $\tilde{\xi}^{* i}<\frac{\int_{\underline{w}^{i}}^{\bar{w}^{i}} h^{i}\left(w^{i}\right) w^{i} d w^{i}}{\sum_{\forall i=1,2} \int_{\underline{w}^{i}}^{\bar{w}^{i}} h^{i}\left(w^{i}\right) w^{i} d w^{i}}$, then $T_{D}^{* i}>\widetilde{T}_{c}^{* i}$ and $T_{D}^{*-i}<\tilde{T}_{c}^{*-i}$. Hence, the per-capita transfer in district $i$ (district $-i$ ) is higher (lower) under a fiscally decentralized economy relative to the transfers adopted in a tax revenue sharing agreement.

\section{Social Choice Between Decentralization Versus Tax Revenue Sharing}

In this section we develop a social welfare analysis of the society's choice between decentralization and tax revenue sharing. Our approach is to compare the society's welfare under decentralization with the corresponding welfare of the society under tax revenue sharing. To state the main result of this section, we define $\Omega_{c}^{i} \alpha^{i}$ as the social marginal utility of income of a household living in district $i$ with wage $w^{i}$ which is the product between, $\Omega_{c}^{i}$, the social marginal utility of a household living in district $i$ with wage $w^{i}$ and its corresponding marginal utility of income $\alpha^{i}$. 
We also define the ratio $T_{j}^{* i} / B_{j}^{*}$ where $T_{j}^{* i}$ is the per capita transfer in district $i$ under fiscal institution $j=$ \{descentralization, tax revenue sharing\}, over the size of resources devoted for public redistribution $B_{j}^{*}$. From conditions (3) and (5) of proposition 1, (see also table 1 in the appendix 2), we show that for economies with and without spillovers, the equilibrium condition for the share of resources for redistribution in each district under fiscal decentralization is given by $T_{D}^{* i} / B_{D}^{*}=s_{D}^{* i}$ where $s_{D}^{* i}=\frac{\int_{\underline{w}^{i}}^{\bar{w}^{i}} h^{i}\left(w^{i}\right) w^{i} d w^{i}}{\sum_{\forall i=1,2} \int_{w^{i}}^{\bar{w}^{i}} h^{i}\left(w^{i}\right) w^{i} d w^{i}} \forall i$ is the share of per capita income of district $i$ in relation to the per capita income of the economy.

For an economy with tax revenue sharing and no spillovers, the share of resources devoted for redistribution in the region $i, T_{C}^{* i} / B_{C}^{*}=\xi^{* i}$, is given by $\xi^{* i}=\frac{\int_{\underline{w}^{i}}^{\bar{w}^{i} h^{i}\left(w^{i}\right) \Omega_{c}^{i} \alpha^{i} d w^{i}}}{\sum_{\forall i=1,2} \int_{\underline{w}^{i}}^{\bar{w}^{i}} h^{i}\left(w^{i}\right) \Omega_{c}^{i} \alpha^{i} d w^{i}} \forall i$, where $\xi^{* i}$ is determined by the share of the average social marginal utility of households in district $i, \int_{\underline{w}^{i}}^{\bar{w}^{i}} h^{i}\left(w^{i}\right) \Omega_{c}^{i} \alpha^{i} d w^{i}$, in relation to the national average social marginal utility of all households in the economy, $\sum_{\forall i=1,2} \int_{\underline{w}^{i}}^{\bar{w}^{i}} h^{i}\left(w^{i}\right) \Omega_{c}^{i} \alpha{ }^{i} d w^{i} \cdot{ }^{19}$ If the economy shows spillovers then $\tilde{\xi}^{* i}=\frac{\Phi^{i}}{\Phi^{i}+\Phi^{-i}} \forall i \quad$ where $\Phi^{i}=\int_{\underline{w}^{i}}^{\bar{w}^{i}} h^{i}\left(w^{i}\right) \Omega_{c}^{i} \alpha^{i} d w^{i}+k^{-i} \int_{\underline{w}^{-i}}^{\bar{w}^{-i}} h^{-i}\left(w^{-i}\right) \Omega_{c}^{-i} \alpha^{-i} d w^{-i} \forall i$.

Lastly, we define $\sigma_{N}\left[\Omega_{c}^{i} \alpha^{i}, \phi^{i}\right]$ as the normalized covariance between the social marginal utility of income of a household $\Omega_{c}^{i} \alpha^{i}$ and $\phi^{i}$ which is the difference between the share of resources devoted for redistribution in the region $i$ under decentralization, $T_{D}^{* i} / B_{D}^{*}$ and the share of resources devoted for redistribution in the region $i$ under tax revenue sharing, $T_{C}^{* i} / B_{C}^{*}$ since $\phi^{i}=\ln \left(T_{D}^{* i} / B_{D}^{*}\right)-\ln \left(T_{C}^{* i} / B_{C}^{*}\right)=\ln \left(s_{D}^{* i}\right)-\ln \left(\xi^{* i}\right)$.Proposition 7 characterizes conditions in which tax revenue sharing dominates (is dominated by) decentralization.

${ }^{19}$ To see this, note that $\Omega_{c}^{i} \alpha^{i}$ is the social marginal utility of income for a family with a wage of $w^{i}$ and $\int_{\underline{w}^{i}}^{\bar{w}^{i}} h^{i}\left(w^{i}\right) \Omega_{c}^{i} \alpha^{i} d w^{i}$ is the average social marginal utility of income of households in district $i$ while $\sum_{\forall i=1,2} \int_{\underline{w}^{i}}^{\bar{w}^{i}} h^{i}\left(w^{i}\right) \Omega_{c}^{i} \alpha^{i} d w^{i}$ is the average social marginal utility of the economy. 
Proposition 7. We define $\sigma_{N}\left[\Omega_{c}^{i} \alpha^{i}, \phi^{i}\right]$ as a normalized covariance between the social marginal utility of income of a household living in district $i$ with wage $w^{i}, \Omega_{c}^{i} \alpha^{i}$, and $\phi^{i}=\ln \left(s_{D}^{* i}\right)-\ln \left(\xi^{* i}\right)$ which is related to the difference between the shares of income in district $i$ in relation to the economy and the share of social marginal utility of income of district $i$ with respect the social marginal utility of income of the economy. Then

$$
\text { 7.1) If } \sigma_{N}\left[\Omega_{c}^{i} \alpha^{i}, \phi^{i}\right] \geq-\sum_{\forall i=1,2} \int_{\underline{w}^{i}}^{\bar{w}^{i}} h^{i}\left(w^{i}\right) \Omega_{c}^{i} \alpha^{i} d w^{i}<0
$$

then decentralization is socially preferred to tax revenue sharing

7.2) If $\sigma_{N}\left[\Omega_{c}^{i} \alpha^{i}, \phi^{i}\right]<-\sum_{\forall i=1,2} \int_{\underline{w}^{i}}^{\bar{w}^{i}} h^{i}\left(w^{i}\right) \Omega_{c}^{i} \alpha^{i} d w^{i}<0$

then tax revenue sharing is socially preferred to decentralization

\section{Proof.}

The equilibrium conditions for decentralization are $\tau_{D}^{* i}=\tau_{D}^{*-i}=\frac{1}{2} \quad \forall i$ and $T_{D}^{* i}=\frac{1}{2} \int_{\underline{w}^{i}}^{\bar{w}^{i}} h^{i}\left(w^{i}\right) w^{i} d w^{i} \forall i$ while the equilibrium conditions for tax revenue sharing are $\tau_{c}^{*}=\tau_{c}^{* i}=\tau_{c}^{*-i}=\frac{1}{2} \quad$ and $T_{c}^{* i}=\frac{\xi^{* i}}{2} \sum_{\forall i=1,2} \int_{\underline{w}^{i}}^{\bar{w}^{i}} h^{i}\left(w^{i}\right) w^{i} d w^{i} \forall i . \quad$ The society's welfare under decentralization is given by

$$
\begin{aligned}
& \Psi_{D}=\sum_{\forall i=1,2} \int_{\underline{w}^{i}}^{\bar{w}^{i}} h^{i}\left(w^{i}\right) \Omega_{c}^{i} v^{i}\left(w^{i}, \tau_{D}^{* i}, T_{D}^{* i}\right) d w^{i}= \\
& \Psi_{D}=\sum_{\forall i=1,2} \int_{\underline{w}^{i}}^{\bar{w}^{i}} h^{i}\left(w^{i}\right) \alpha^{i}\left\{\ln \left(\frac{w^{i}}{2}\right)+\ln \left(\frac{\int_{\underline{w}^{i}}^{\bar{w}^{i}} h^{i}\left(w^{i}\right) w^{i} d w^{i}}{2}\right)\right\} d w^{i}
\end{aligned}
$$

And the society's welfare under tax revenue sharing is

$$
\begin{gathered}
\Psi_{c}=\sum_{\forall i=1,2} \int_{\underline{w}^{i}}^{\bar{w}^{i}} h^{i}\left(w^{i}\right) \Omega_{c}^{i} v^{i}\left(w^{i}, \tau_{c}^{* i}, T_{c}^{* i}\right) d w^{i} \\
\Rightarrow \quad \Psi_{c}=\sum_{\forall i=1,2} \int_{\underline{w}^{i}}^{\bar{w}^{i}} h^{i}\left(w^{i}\right) \Omega_{c}^{i} \alpha^{i}\left\{\ln \left(\frac{w^{i}}{2}\right)\right\} d w^{i}+
\end{gathered}
$$




$$
+\sum_{\forall i=1,2} \int_{\underline{w}^{i}}^{\bar{w}^{i}} h^{i}\left(w^{i}\right) \Omega_{c}^{i} \alpha^{i}\left\{\ln \left(\frac{\xi^{* i}}{2} \sum_{\forall i=1,2} \int_{\underline{w}^{i}}^{\bar{w}^{i}} h^{i}\left(w^{i}\right) w^{i} d w^{i}\right)\right\} d w^{i}
$$

Therefore decentralization is preferred to tax revenue sharing if $\Psi_{D}-\Psi_{C}>$ 0 , and tax revenue sharing is preferred if $\Psi_{D}-\Psi_{c}<0$. And

$$
\Psi_{D}-\Psi_{c}=\sum_{\forall i=1,2} \int_{\underline{w}^{i}}^{\bar{w}^{i}} h^{i}\left(w^{i}\right) \alpha^{i} \phi^{i} d w^{i}
$$

Where

$$
\phi^{i}=\ln \left(T_{D}^{* i} / B_{D}^{*}\right)-\ln \left(T_{C}^{* i} / B_{C}^{*}\right)=\ln \left(s_{D}^{* i}\right)-\ln \left(\xi^{* i}\right)
$$

By definition of a covariance $\sigma[X, Y]$ between variables $X$ and $Y, \sigma[X, Y]=$ $E[X Y]-E[X] E[Y]$, state condition (50) as follows:

$$
\begin{array}{r}
\sum_{\forall i=1,2} \int_{\underline{w}^{i}}^{\bar{w}^{i}} h^{i}\left(w^{i}\right) \alpha^{i} \phi^{i} d w^{i}=\sigma\left[\Omega_{c}^{i} \alpha^{i}, \phi^{i}\right]+ \\
+\sum_{\forall i=1,2} \int_{\underline{w}^{i}}^{\bar{w}^{i}} h^{i}\left(w^{i}\right) \Omega_{c}^{i} \alpha^{i} d w^{i} \sum_{\forall i=1,2} \int_{\underline{w}^{i}}^{\bar{w}^{i}} h^{i}\left(w^{i}\right) \phi^{i} d w^{i}
\end{array}
$$

Define the normalized covariance $\sigma_{N}\left[\Omega_{c}^{i} \alpha^{i}, \phi^{i}\right]$ between $\Omega_{c}^{i} \alpha^{i}$ and $\phi^{i}$ as follows:

$$
\sigma_{N}\left[\Omega_{c}^{i} \alpha^{i}, \phi^{i}\right]=\frac{\sigma\left[\Omega_{c}^{i} \alpha^{i}, \phi^{i}\right]}{\sum_{\forall i=1,2} \int_{\underline{w}^{i}}^{\bar{w}^{i}} h^{i}\left(w^{i}\right) \phi^{i} d w^{i}}
$$

Therefore, from (50), (52) and $\sigma_{N}\left[\Omega_{c}^{i} \alpha^{i}, \phi^{i}\right] \frac{>}{<}-\sum_{\forall i=1,2} \int_{\underline{w}^{i}}^{\bar{w}^{i}} h^{i}\left(w^{i}\right) \Omega_{c}^{i} \alpha^{i} d w^{i}<0$ implies $\Psi_{D} \geq \Psi_{c}$.

Proposition 7 says that if the normalized covariance $\sigma_{N}\left[\Omega_{c}^{i} \alpha^{i}, \phi^{i}\right]$ between he social marginal utility of income of a household living in district $i$ with wage $w^{i}, \Omega_{c}^{i} \alpha^{i}$, and $\phi^{i}=\ln \left(s_{D}^{* i}\right)-\ln \left(\xi^{* i}\right)$ which is the natural $\log$ of the difference between the shares of income in district $i$ in relation to the economy and the share of the social marginal utility of income of district $i$ with respect to the social marginal utility of income of the economy is significantly negative (that is if $\left.\sigma_{N}\left[\Omega_{c}^{i} \alpha^{i}, \phi^{i}\right]<-\sum_{\forall i=1,2} \int_{\underline{w}^{i}}^{\bar{w}^{i}} h^{i}\left(w^{i}\right) \Omega_{c}^{i} \alpha^{i} d w^{i}<0\right)$ then tax revenue sharing welfare dominates decentralization. 
The intuition behind these results is straightforward: One of the main predictions of our model is that tax revenue sharing will allocate a different amount of resources for public redistribution in each district relative the institution of fiscal decentralization. This means that if we change from tax revenue sharing to decentralization then the size of per capita transfers to the poor corresponding to the local government will increase in some regions and will decrease in other regions. If the per capita transfer increases in region $i$ then the welfare of residents of this district will also increase, which in turn becomes the welfare benefit to motivate a change from a tax revenue sharing policy to a decentralization policy. Simultaneously, if the per capita transfer decreases in other regions, say regions $-i$, then the welfare of the residents of districts $-i$ will also decrease which in turn becomes the welfare cost to move from tax revenue sharing to decentralization.

Condition (7.2) says that if the normalized covariance $\sigma_{N}\left[\Omega_{c}^{i} \alpha^{i}, \phi^{i}\right]$ is significantly negative then tax revenue sharing welfare dominates decentralization because, as a result of a change from tax revenue sharing to decentralization, the size of the government's transfers decrease (increase) in districts with higher (lower) than average marginal social utilities of income. In this case, the welfare cost outweighs the benefit from changing from a tax revenue sharing policy to a decentralization one (this is condition 7.2 in proposition 7).

Similarly, condition (7.1) identifies examples in which decentralization welfare dominates tax revenue sharing. An example is that if the normalized covariance $\sigma_{N}\left[\Omega_{c}^{i} \alpha^{i}, \phi^{i}\right]$ is positive then those districts who gain by having a higher size of per capita transfers (due to a change from tax revenue to decentralization) are precisely those districts with higher than average marginal social utility of income in the economy's social welfare function. As a result, the welfare gains from those districts resulting from a higher size of per capita transfers (associated with a change from tax revenue to decentralization) outweigh the loss in welfare of districts in which the per capita transfers will decrease as a result of a change from tax revenue to decentralization. The net result will be that the society's welfare will increase if the economy shifts from tax revenue sharing to fiscal decentralization.

\section{Calibration of the Model}

In this section we calibrate the model to highlight the differences in the interregional allocation of resources to redistribute income under fiscal decentralization and tax revenue sharing. In table 1 , see the appendix 2 , we show the equilibrium conditions of the tax rate, the per-capita public transfer for each state or local government, the size of resources designated for public redistribution in the economy, and the shares of resources for public redistribution allocated in each district for economies with fiscal 
decentralization and tax revenue sharing. Our model predicts that the tax rates and the size of resources devoted for public redistribution would be the same under decentralization and tax revenue sharing, while the inter-regional allocation would be different under these institutions. ${ }^{20}$

Our model makes predictions on the per capita transfers in each district and on the shares of resources from redistribution designated to each district. Section 4 also shows that the welfare analysis of the society's choice between decentralization and tax revenue sharing depends critically on the different allocations between these two fiscal institutions of the shares of resources assigned for public redistribution in each district. Hence the calibration of our model is primarily focused on the shares of resources from redistribution allocated in each district.

As we mentioned before, the ratio $T_{j}^{* i} / B_{j}^{*}$ where $T_{j}^{* i}$ is the per capita transfer in district $i$ under fiscal institution $j=\{$ descentralization, tax revenue sharing $\}$, over the size of resources designated for public redistribution $B_{j}^{*}$. From conditions (3) and (5) of proposition 1 , (see also table 1 in the appendix 2), we show that under fiscal decentralization, the equilibrium condition for the share of resources for redistribution in each district is given by $\frac{T_{D}^{* i}}{B_{D}^{*}}=\frac{\int_{\underline{w}^{i}}^{\bar{w}^{i}} h^{i}\left(w^{i}\right) w^{i} d w^{i}}{\sum_{\forall i=1,2} \int_{\underline{w}^{i}}^{\bar{w}^{i}} h^{i}\left(w^{i}\right) w^{i} d w^{i}} \forall i$ which is the share of per capita income of district $i$ in relation to the per capita income of the economy. To calibrate $\frac{T_{D}^{* i}}{B_{D}^{*}}$ we use the distribution of per capita state income for Mexico from the Instituto Nacional de Estadística y Geografía (INEGI) for the year 2014.

For an economy with tax revenue sharing, the ratio of resources designated for redistribution in the region $i$ is given by

${ }^{20}$ Indeed, for an economy without spillovers, table 1 shows the equilibrium conditions for the tax rate under decentralization which is given by $\tau_{D}^{* i}=\tau_{D}^{*-i}=\frac{1}{2}$, while the equilibrium tax rate under tax revenue sharing is $\tau_{c}^{*}=\tau_{c}^{* i}=\tau_{c}^{*-i}=\frac{1}{2}$. Moreover, the amount of resources designated for public redistribution under decentralization, $B_{D}^{*}$, and tax revenue sharing, $B_{c}^{*}$, are $B_{D}^{*}=B_{c}^{*}=\frac{\sum_{\forall i=1,2} \int_{\underline{w}^{i}}^{\bar{w}^{i} h^{i}\left(w^{i}\right) w^{i} d w^{i}}}{2}$. In addition, the per capita transfer in district $i$ under decentralization is $T_{D}^{* i}=\frac{1}{2} \int_{\underline{w}^{i}}^{\bar{w}^{i}} h^{i}\left(w^{i}\right) w^{i} d w^{i} \quad \forall i$ while under tax revenue sharing $T_{c}^{* i}=\frac{\xi^{* i}}{2} \sum_{\forall i=1,2} \int_{\underline{w}^{i}}^{\bar{w}^{i}} h^{i}\left(w^{i}\right) w^{i} d w^{i}$ with $\xi^{* i} \in(0,1)$. Similar results are given for an economy with spillovers, see table 1 . 
$\frac{T_{C}^{* i}}{B_{C}^{*}}=\xi^{* i}=\frac{\int_{\underline{w}^{i}}^{\bar{w}^{i}} h^{i}\left(w^{i}\right) \Omega_{c}^{i} \alpha^{i} d w^{i}}{\sum_{\forall i=1,2} \int_{\underline{w}^{i}}^{\bar{w}^{i}} h^{i}\left(w^{i}\right) \Omega_{C}^{i} \alpha^{i} d w^{i}} \forall i$, where $\frac{T_{C}^{* i}}{B_{C}^{*}}$ is determined by the share of the average social marginal utility of households in district $i, \int_{\underline{w}^{i}}^{\bar{w}^{i}} h^{i}\left(w^{i}\right) \Omega_{c}^{i} \alpha^{i} d w^{i}$, in relation to the national average social marginal utility of all households in the economy, $\sum_{\forall i=1,2} \int_{w^{i}}^{\bar{w}^{i}} h^{i}\left(w^{i}\right) \Omega_{c}^{i} \alpha^{i} d w^{i}$. To calculate $T_{C}^{* i} / B_{C}^{*}$ we need to calibrate values for the social marginal utility of income $\Omega_{c}^{i} \alpha^{i}$ of a household living in district $i$ with wage $w^{i}$ which is the product between, $\Omega_{c}^{i}$, the social marginal utility of a household living in district $i$ with wage $w^{i}$ and its corresponding marginal utility of income $\alpha^{i}$.

To do so, we follow the classical treatment on optimal taxation from Atkinson and Stiglitz (1976) and consider that $\Omega_{c}^{i} \alpha^{i}$ is an inverse function of income. There are several reasons why this assumption is appealing: first, the marginal utility of income might be decreasing with income which implies that the lower the income of the household, the higher the marginal utility of income $\alpha^{i}$, and the higher $\Omega_{c}^{i} \alpha^{i}$. Second, policy makers might be concerned with the well being of households with low income. Hence, the lower the income of the household, the higher the social marginal utility of the household in the welfare function $\Omega_{c}^{i}$ and the higher $\Omega_{c}^{i} \alpha^{i}$

Thus, to calibrate the average social marginal income of households in district $i, \int_{\underline{w}^{i}}^{\bar{w}^{i}} h^{i}\left(w^{i}\right) \Omega_{c}^{i} \alpha^{i} d w^{i} \forall i$, we use two different approaches: first, we use the inverse of the per capita income in each state, and second we use a Paretian distribution of income which captures the inequality in the distribution of income observed in modern economies. In our first approach, to estimate the average social marginal utility of income in each state, we use the inverse of the per capita income at the state level with data from INEGI 2014 (see table 2 in the appendix 2). Therefore, $\int_{\underline{w}^{i}}^{\bar{w}^{i}} h^{i}\left(w^{i}\right) \Omega_{c}^{i} \alpha^{i} d w^{i}=\frac{1}{Y_{i}^{p}}$ where $Y_{i}^{p}$ is per capita income in state $i$.

In the case of the Paretian distribution, we use the probability distribution function of the Paretian distribution given by

$$
\frac{T_{C}^{* i}}{B_{C}^{*}}=\left\{\begin{array}{cc}
\frac{\theta\left(Y_{\min }^{p}\right)^{\theta}}{Y_{i}^{p}} & \text { for } \theta>0, Y_{i}^{p} \geq Y_{\min }^{p} \text { and } Y_{\min }^{p}=\min \left\{Y_{i}^{p}\right\}_{\forall i} \\
0 & \text { for } Y_{i}^{p}<Y_{\min }^{p}
\end{array}\right.
$$


Where $Y_{i}^{p}$ is per capita income in state $i, \theta>0$ is a scale parameter of the Paretian distribution that captures the preference for inter-regional equity of a benevolent social planner (the higher $\theta$ the higher the preference for achieving a more equitable allocation of inter-regional resources) and $Y_{\min }^{p}=\min \left\{Y_{i}^{p}\right\}_{\forall i}$.

For a comparison of our calibration example between the share of resources for redistribution allocated at the state level under fiscal decentralization and tax revenue sharing for an economy without inter regional spillovers see graph 1 and table 2 of the appendix 2 . The share of resources by district under tax revenue sharing, $T_{C}^{* i} / B_{C}^{*}$, is calculated in three different cases: as we mentioned before, the first case estimates the average social marginal utility of income of households in each district through the inverse of the per capita state income and in the other two cases we use the Paretian distribution function for values of $\theta=1$ and $\theta=2$.

Our results show a sharp distinction between the resources allocated for public redistribution under the institutions of fiscal decentralization and tax revenue sharing. Under decentralization, the districts with more resources devote a higher proportion of the economy's resources for redistribution. This is because the higher the per capita income in the state, the higher the equilibrium level of $T_{D}^{* i}$ implying higher levels of $T_{D}^{* i} / B_{D}^{*}$ (see condition 3 in proposition 1). Our analysis suggests that under fiscal decentralization, the three sub national governments with the lowest per capita income would allocate only $4.6 \%$ of the economy's resources for redistribution while the three sub national governments with the highest per capita income would allocate $17.84 \%$ of the economy's resources for redistribution.

In contrast to the institution of fiscal decentralization, that will not minimize the inter-regional inequality of income, under tax revenue sharing the issue of inter-regional equity becomes an important objective of public policy. Therefore, an optimal policy of tax revenue sharing will allocate significant resources to those regions with high social marginal utility of income and, therefore, more resources might be allocated to districts with low income. The preference for inter-regional equity is more prominent in the Paretian distribution with $\theta=2$, since our model suggests that the three sub national governments with the lowest per capita income would receive $38 \%$ of the economy's resources for redistribution. 


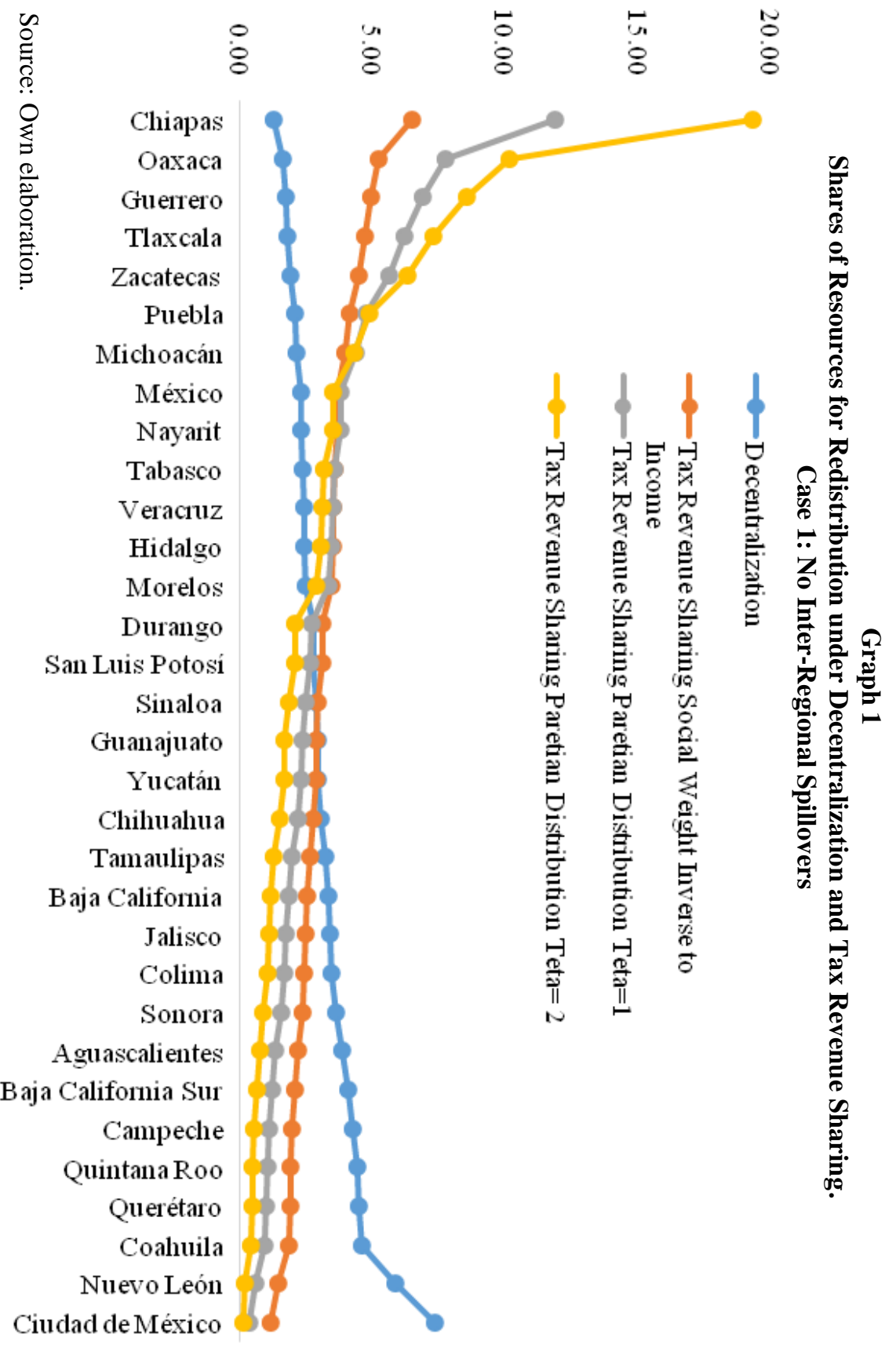


Under the Paretian distribution with $\theta=1$, the three sub national governments with the lowest per capita income would receive $26.5 \%$, and under the social welfare function in which the marginal social utility of income is inversely related to per capita income they would receive $16.7 \%$ of the economy's resources for redistribution. For the three states with the highest per capita income they would receive, respectively, the $0.7 \%$ under the Paretian distribution with $\theta=2,2.2 \%$ under the Paretian distribution with $\theta=1$, and $4.4 \%$ of the economy's resources for redistribution if the marginal social utility of income is inversely related to per capita income.

For an economy with inter regional spillovers we need to estimate the extent of the spillovers. In the context of redistribution, inter-regional spillovers might arise because of an inter-dependence of the well being of households living in different regions (for instance a father who lives in region $i$ who cares for the well being of a relative who lives in region $-i$ and vice versa). In this context, spillovers occur when a household living in region, say $-i$, receives public transfers and the household living in region $i$ cares about the well being of the household which benefits in region $-i$ from the public redistribution. In this case, we say that there is an spillover effect from the public redistribution implemented in region $-i$.

In this paper we assume that the higher the population in a state, the higher the chances for the existence of an interdependent utility function with individuals in other regions. This implies, that the higher the population in the state, the higher is the rate of spillovers of that state over other regions. Therefore, we calibrate the extent of inter-regional spillovers from redistribution with the density of population at the state level using data from the "Censo 2010" provided by INEGI. For an economy with inter regional spillovers, our calculations are displayed in graph two (see below) and in Table 3 in the appendix 2.

In this economy, fiscal decentralization is a better mechanism to incorporate the inter-regional heterogeneity of preferences for public policy than tax revenue sharing. However, redistribution under tax revenue sharing has two important advantages over decentralization: first, redistribution with spillovers will be Pareto efficient under tax revenue sharing while Pareto inefficient under decentralization. Second, tax revenue sharing leads to a social welfare gain (relative decentralization) due to a more equitable interregional allocation of resources. 


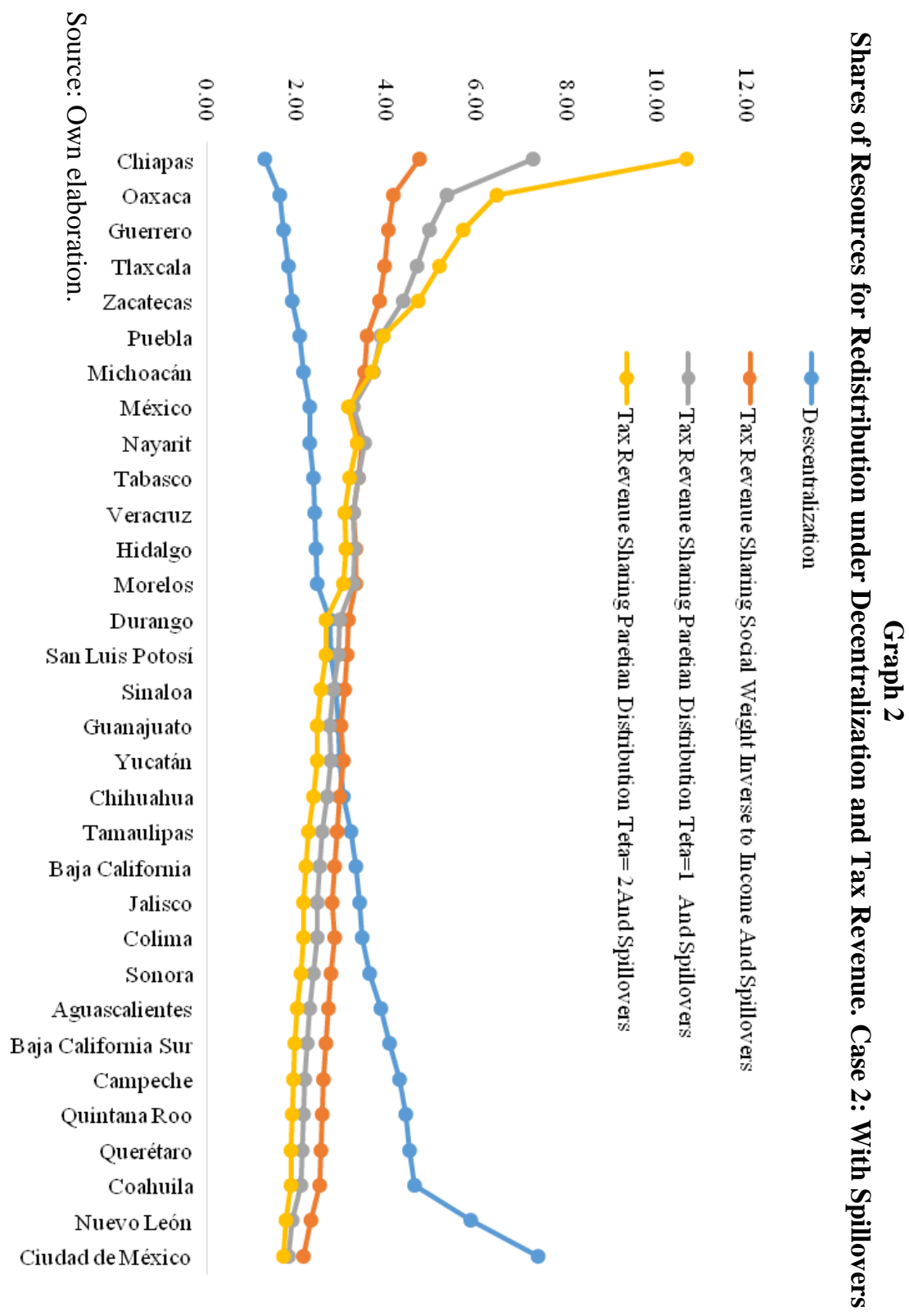


The distribution of $T_{D}^{* i} / B_{D}^{*}$ under spillovers is the same as in the case of no spillovers (since fiscal decentralization does not incorporate the spillover effects from redistribution). As we mentioned before, under decentralization, those districts with more resources designate a higher proportion of the economy's resources for redistribution. The model suggests that the three sub national governments with the lowest per capita income would receive only $4.6 \%$ of the economy's resources for redistribution while the three sub national governments with the highest per capita income would use $17.84 \%$ of the economy's resources for redistribution.

Under tax revenue sharing with spillovers from redistribution, the three sub national governments with the lowest per capita income would receive $22.7 \%$ of the economy's resources for redistribution under the Paretian distribution with $\theta=2$, the $17.5 \%$ under the Paretian distribution with $\theta=1$, and the $12.9 \%$ of the economy's resources for redistribution under the social welfare function in which the marginal social utility of income is inversely related to per capita income. For the three states with the highest per capita income they would receive, respectively, the $5.3 \%$ under the Paretian distribution with $\theta=2,5.8 \%$ under the Paretian distribution with $\theta=1$, and $6.9 \%$ of the economy's resources for redistribution if the marginal social utility of income is inversely related to per capita income.

In summary, under fiscal decentralization, the distribution of shares of resources allocated for redistribution is positively related with the state's own resources. Poor households benefit from a higher amount designated to public redistribution if the household lives in states with high per capita income. In contrast, an equitable allocation of resources across states is an important goal of policy making under tax revenue sharing. Therefore, tax revenue sharing is likely to redistribute more resources to states with lower than average income. As a result, the distribution of shares of resources allocated for redistribution is negatively related with the state's own resources. Poor households benefit from a higher amount designated to public redistribution if the household lives in states with low per capita income.

The calibration of the model also suggests that there are significant differences in the shares of resources allocated for redistribution for economies with and without spillovers. In particular, our model suggests that, if policy makers take into account not only inter-regional equity but also inter-regional efficiency in the allocation of resources for redistribution, then the amount of resources allotted to redistribution by the states with the lowest per capita income is lower in the case of spillovers relative to the case of no spillovers. 
To see this (see table 4 in the appendix 2), note that, in the case of no spillovers, the three sub national governments with the lowest per capita income would receive $38 \%$ of the economy's resources for redistribution, under the Paretian distribution with $\theta=2$ while in the case of spillovers they would receive $22.7 \%$. In the case of a Paretian distribution with $\theta=1$, the three sub national governments with the lowest per capita income and no spillovers would receive $26.5 \%$ and with spillovers they would receive $17.5 \%$, and under the social welfare function in which the marginal social utility of income is inversely related to per capita income with no spillovers they would receive $16.7 \%$, and in the case of spillovers, $12.9 \%$ of the economy's resources for redistribution.

\section{Discussion of the Results and Implications for Policy Design}

In this paper we study the size and regional distribution of public transfers with and without spillovers under two different fiscal institutions: fiscal decentralization (in which failures of coordination among sub-national governments might arise) versus tax revenue sharing as a coordination tax policy among different tiers of governments. It is worthwhile to develop such a comparative analysis because it is empirically relevant and, more importantly, because knowing the effect of different forms of fiscal institutions related to the efficiency of the government's programs would help us to identify potential advantages and shortcomings of feasible policy options.

The main predictions of our theory are the following: first, surprisingly, our models find that the government's effort to redistribute income (the size of the national budget for public redistribution) is the same for both types of fiscal institutions. This finding is satisfied for economies with and without regional spillovers from public redistribution. Second, the choice of fiscal institutions lead to differences in the regional allocation of public transfers due to the decentralization and tax revenue sharing policies differently aggregating the demands for public redistribution. We show that the distribution of preferences from local spending and the distribution of income explain these differences.

To be more specific, for the case in which public redistribution does not show inter-regional spillovers, the size of public transfers under fiscal decentralization depend only on the average wage of the district while under tax revenue sharing depends on the national average wage and the share of funds to be allocated in the district which is given by the ratio between the distribution of social marginal benefits from public transfers in the district in relation to the national distribution of social marginal benefits. If the share of funds in the district in the tax revenue sharing agreement is lower (higher) than the share of the average wage in the district in relation to the national 
average wage then the size of the per-capita public transfer received by a resident of the district under fiscal decentralization is higher (lower) than that received under the fiscal institution of tax revenue sharing.

Another relevant implication for policy design in our study is that the optimal formulas for revenue sharing do not depend on the relative contribution of tax revenue of each district (that is, the amount of tax revenue that is collected in each district). This outcome has important implications on the design of formulas for tax revenue sharing because in practice most countries design formulas that take into account how much tax revenue local governments contribute to a general fund. Our paper suggests that the optimal design of formulas should depend only on the district's relative distribution of marginal benefits in relation to the national marginal benefits of public spending.

In our model in which public transfers show spillovers, fiscal decentralization will not lead to Pareto efficient public transfers while the government's transfers under tax coordination and revenue sharing are Pareto efficient. Intuition might suggest that because revenue sharing internalizes interregional spillovers then the size of public transfers under coordinated tax policies would be higher relative to those transfers under fiscal decentralization. However, this is not necessarily the case. In this paper we identify conditions in which the opposite occurs.

Finally, for the case in which public redistribution shows spillovers, these outcomes suggest a tradeoff between efficiency and the regional size of public transfers. $^{21}$ This tradeoff could have important implications on the regional and national efficacy of the government's effort to redistribute income. In particular, if income inequality is concentrated in some key districts then the government's redistributive program could be more (less) effective in redistributing welfare to the poor under a fiscally decentralized economy relative to the social welfare achieved under a tax revenue sharing agreement.

\section{References}

[1] Atkinson, A.B. and J.E. Stiglitz. (1976). "The design of tax structure: Direct versus indirect taxation", Journal of Public Economics 6, 55-75.

[2] Bergstrom, T. (1995). "A survey of theories of the family", In Rosenzweig, M.R., and O. Stark (Eds), Handbook of Population and Family Economics, Vol. 1, Elsevier, Amsterdam, The Netherlands.

[3] Boadway, R., and Keen, M. (1996). "Efficiency and the optimal direction for federal-state transfers", International Tax and Public Finance, 3(2), 137-155.

[4] Johnson, W. R. (1988). "Income redistribution in a federal system", American

\footnotetext{
${ }^{21}$ This is to say that, under spillovers, tax revenue sharing leads to Pareto efficient transfers but at a smaller size in key districts compared with larger but Pareto inefficient transfers under fiscal decentralization.
} 
Economic Review, 78(3): 570-573.

[5] Keen, M. (1998). "Vertical tax externalities in the theory of fiscal federalism". IMF Staff Papers, 45,(3), 454-485.

[6] Devereuxa M.P., Lockwood, B., Redoanoa, M. (2007). "Horizontal and vertical indirect tax competition: Theory and some evidence from the USA". Journal of Public Economics, 91, (3-4), 451-479.

[7] Kochi, I. and Ponce-Rodríguez, R.A. (2016), “Optimal formulas for subnational tax revenue sharing", Theoretical Economics Letters, 6, 808-818.

[8] Martinez-Vazquez, J., Lago-Peñas, S., Sacchi, A. (2015), "The impact of fiscal decentralization: a survey", GEN Working Paper A 2015-5, 1-30.

[9] Oates, Wallace E. (1972). Fiscal Federalism. New York: Harcourt, Brace, Jovanovich.

[10] Pauly, M.V. (1973). "Income redistribution as a local public good", Journal of Public Economics, 2(1), 35-58.

[11] Ponce-Rodríguez, R.A. Hankla, C.R., Martinez-Vazquez, J. and Heredia-Ortiz, E. (2016). "Political institutions and federalism: a "strong" decentralization theorem", International Center for Public Policy, Working Paper Series, AYSPS, Georgia State University, paper1603.

[12] Rao, M.G. (2007). "Resolving fiscal imbalances: issues in tax sharing" In R. A. Boadway and A. Shah (Eds), Intergovernmental Transfers, Principles and Practice, Washington, D.C: The World Bank.

[13] Wilson, J.D. (1999). "Theories of tax competition", National Tax Journal, 52(2), 269-304.

[14] Wilson, L.S. (2007), "Macro formulas for equalization", En Boadway, R. A. and Shah A. (Eds), Intergovernmental Transfers, Principles and Practice, Washington, D.C: The World Bank. 


\section{Appendix 1}

\section{Proposition 5. If}

$k^{i}\left(\int_{\underline{w}^{i}}^{\bar{w}^{i}} h^{i}\left(w^{i}\right) \Omega_{c}^{i} \alpha^{i} d w^{i}\right)^{2} \geq k^{-i}\left(\int_{\underline{w}^{-i}}^{\bar{w}^{-i}} h^{-i}\left(w^{-i}\right) \Omega_{c}^{-i} \alpha^{-i} d w^{-i}\right)^{2}$, then $\xi^{* i} \geq \tilde{\xi}^{* i}$.

\section{Proof.}

Assume

$$
k^{i}\left(\int_{\underline{w}^{i}}^{\bar{w}^{i}} h^{i}\left(w^{i}\right) \Omega_{c}^{i} \alpha^{i} d w^{i}\right)^{2} \frac{>}{<} k^{-i}\left(\int_{\underline{w}^{-i}}^{\bar{w}^{-i}} h^{-i}\left(w^{-i}\right) \Omega_{c}^{-i} \alpha^{-i} d w^{-i}\right)^{2}
$$

Then add the term $+k^{-i} \int_{\underline{w}^{-i}}^{\bar{w}^{-i}} h^{-i}\left(w^{-i}\right) \Omega_{c}^{-i} \alpha^{-i} d w^{-i} \int_{\underline{w}^{i}}^{\bar{w}^{i}} h^{i}\left(w^{i}\right) \Omega_{c}^{i} \alpha^{i} d w^{i}$ at both sides of the inequality to show

$$
\begin{gathered}
k^{i}\left(\int_{\underline{w}^{i}}^{\bar{w}^{i}} h^{i}\left(w^{i}\right) \Omega_{c}^{i} \alpha^{i} d w^{i}\right)^{2} \\
+k^{-i} \int_{\underline{w}^{-i}}^{\bar{w}^{-i}} h^{-i}\left(w^{-i}\right) \Omega_{c}^{-i} \alpha^{-i} d w^{-i} \int_{\underline{w}^{i}}^{\bar{w}^{i}} h^{i}\left(w^{i}\right) \Omega_{c}^{i} \alpha^{i} d w^{i} \frac{\geq}{<} \\
k^{-i}\left(\int_{\underline{w}^{-i}}^{\bar{w}^{-i}} h^{-i}\left(w^{-i}\right) \Omega_{c}^{-i} \alpha^{-i} d w^{-i}\right)^{2} \\
+k^{-i} \int_{\underline{w}^{-i}}^{\bar{w}^{-i}} h^{-i}\left(w^{-i}\right) \Omega_{c}^{-i} \alpha^{-i} d w^{-i} \int_{\underline{w}^{i}}^{\bar{w}^{i}} h^{i}\left(w^{i}\right) \Omega_{c}^{i} \alpha^{i} d w^{i} \\
\Rightarrow
\end{gathered}
$$

Now add the term $\int_{\underline{w}^{i}}^{\bar{w}^{i}} h^{i}\left(w^{i}\right) \Omega_{c}^{i} \alpha^{i} d w^{i} \sum_{\forall i,-i} \int_{\underline{w}^{i}}^{\bar{w}^{i}} h^{i}\left(w^{i}\right) \Omega_{c}^{i} \alpha^{i} d w^{i}$ at both sides of the inequality to obtain

$$
\begin{array}{r}
\int_{\underline{w}^{i}}^{\bar{w}^{i}} h^{i}\left(w^{i}\right) \Omega_{c}^{i} \alpha^{i} d w^{i} \sum_{\forall i,-i} \int_{\underline{w}^{i}}^{\bar{w}^{i}} h^{i}\left(w^{i}\right) \Omega_{c}^{i} \alpha^{i} d w^{i}+k^{i}\left(\int_{\underline{w}^{i}}^{\bar{w}^{i}} h^{i}\left(w^{i}\right) \Omega_{c}^{i} \alpha^{i} d w^{i}\right)^{2} \\
+k^{-i} \int_{\underline{w}^{-i}}^{\bar{w}^{-i}} h^{-i}\left(w^{-i}\right) \Omega_{c}^{-i} \alpha^{-i} d w^{-i} \int_{\underline{w}^{i}}^{\bar{w}^{i}} h^{i}\left(w^{i}\right) \Omega_{c}^{i} \alpha^{i} d w^{i} \frac{\geq}{<}
\end{array}
$$




$$
\begin{aligned}
& \int_{\underline{w}^{i}}^{\bar{w}^{i}} h^{i}\left(w^{i}\right) \Omega_{c}^{i} \alpha^{i} d w^{i} \sum_{\forall i,-i} \int_{\underline{w}^{i}}^{\bar{w}^{i}} h^{i}\left(w^{i}\right) \Omega_{c}^{i} \alpha^{i} d w^{i} \\
& +k^{-i} \int_{\underline{w}^{-i}}^{\bar{w}^{-i}} h^{-i}\left(w^{-i}\right) \Omega_{c}^{-i} \alpha^{-i} d w^{-i}\left[\sum_{\forall i,-i} \int_{\underline{w}^{i}}^{\bar{w}^{i}} h^{i}\left(w^{i}\right) \Omega_{c}^{i} \alpha^{i} d w^{i}\right]
\end{aligned}
$$

Re-arrange terms to show:

$$
\begin{gathered}
\int_{\underline{w}^{i}}^{\bar{w}^{i}} h^{i}\left(w^{i}\right) \Omega_{c}^{i} \alpha^{i} d w^{i}\left[\sum_{\forall i,-i} \int_{\underline{w}^{i}}^{\bar{w}^{i}} h^{i}\left(w^{i}\right) \Omega_{c}^{i} \alpha^{i} d w^{i}+k^{i} \int_{\underline{w}^{i}}^{\bar{w}^{i}} h^{i}\left(w^{i}\right) \Omega_{c}^{i} \alpha^{i} d w^{i}\right. \\
\left.+k^{-i} \int_{\underline{w}^{-i}}^{\bar{w}^{-i}} h^{-i}\left(w^{-i}\right) \Omega_{c}^{-i} \alpha^{-i} d w^{-i}\right] \frac{\geq}{<} \\
{\left[\int_{\underline{w}^{i}}^{\bar{w}^{i}} h^{i}\left(w^{i}\right) \Omega_{c}^{i} \alpha^{i} d w^{i}\right.} \\
\left.+k^{-i} \int_{\underline{w}^{-i}}^{\bar{w}^{-i}} h^{-i}\left(w^{-i}\right) \Omega_{c}^{-i} \alpha^{-i} d w^{-i}\right] \sum_{\forall i,-i} \int_{\underline{w}^{i}}^{\bar{w}^{i}} h^{i}\left(w^{i}\right) \Omega_{c}^{i} \alpha^{i} d w^{i}
\end{gathered}
$$

Express the last equations as follows

$$
\frac{\int_{\underline{w}^{i}}^{\bar{w}^{i}} h^{i}\left(w^{i}\right) \Omega_{c}^{i} \alpha^{i} d w^{i}}{\sum_{\forall i,-i} \int_{\underline{w}^{i}}^{\bar{w}^{i}} h^{i}\left(w^{i}\right) \Omega_{c}^{i} \alpha^{i} d w^{i}}>
$$

$$
\int_{\underline{w}^{i}}^{\bar{w}^{i}} h^{i}\left(w^{i}\right) \Omega_{c}^{i} \alpha^{i} d w^{i}+k^{-i} \int_{\underline{w}^{-i}}^{\bar{w}^{-i}} h^{-i}\left(w^{-i}\right) \Omega_{c}^{-i} \alpha^{-i} d w^{-i}
$$

$\overline{\sum_{\forall i,-i} \int_{\underline{w}^{i}}^{\bar{w}^{i}} h^{i}\left(w^{i}\right) \Omega_{c}^{i} \alpha^{i} d w^{i}+k^{i} \int_{\underline{w}^{i}}^{\bar{w}^{i}} h^{i}\left(w^{i}\right) \Omega_{c}^{i} \alpha^{i} d w^{i}+k^{-i} \int_{\underline{w}^{-i}}^{\bar{w}^{-i}} h^{-i}\left(w^{-i}\right) \Omega_{c}^{-i} \alpha^{-i} d w^{-i}}$

Since $\quad \Phi^{i}=\int_{\underline{w}^{i}}^{\bar{w}^{i}} h^{i}\left(w^{i}\right) \Omega_{c}^{i} \alpha^{i} d w^{i}+k^{-i} \int_{\underline{w}^{-i}}^{\bar{w}^{-i}} h^{-i}\left(w^{-i}\right) \Omega_{c}^{-i} \alpha^{-i} d w^{-i} \quad$ and $\Phi^{-i}=\int_{\underline{w}^{-i}}^{\bar{w}^{-i}} h^{-i}\left(w^{-i}\right) \Omega_{c}^{-i} \alpha^{-i} d w^{-i}+k^{i} \int_{\underline{w}^{i}}^{\bar{w}^{i}} h^{i}\left(w^{i}\right) \Omega_{c}^{i} \alpha^{i} d w^{i}$, use these definitions on the right hand side of the inequality

$$
\frac{\int_{\underline{w}^{i}}^{\bar{w}^{i}} h^{i}\left(w^{i}\right) \Omega_{c}^{i} \alpha^{i} d w^{i}}{\sum_{\forall i,-i} \int_{\underline{w}^{i}}^{\bar{w}^{i}} h^{i}\left(w^{i}\right) \Omega_{c}^{i} \alpha^{i} d w^{i}} \frac{>}{<} \frac{\Phi^{i}}{\Phi^{i}+\Phi^{-i}}
$$


Now

$$
\xi^{* i}=\frac{\int_{\underline{w}^{i}}^{\bar{w}^{i}} h^{i}\left(w^{i}\right) \Omega_{c}^{i} \alpha^{i} d w^{i}}{\sum_{\forall i,-i} \int_{\underline{w}^{i}}^{\bar{w}^{i}} h^{i}\left(w^{i}\right) \Omega_{c}^{i} \alpha^{i} d w^{i}}
$$

And

Therefore,

$$
\tilde{\xi}^{* i}=\frac{\Phi^{i}}{\Phi^{i}+\Phi^{-i}}
$$

$$
\xi^{* i} \frac{>}{<} \tilde{\xi}^{* i}
$$




\section{Appendix 2}

\section{Table 1 \\ Equilibrium Conditions under Fiscal Decentralization and Tax Revenue Sharing}

Case 1: No Spillovers

\section{Policy Under \\ Decentralization}

Policy Under Tax Revenue Sharing

Tax Rate in

District $i$

Per-Capita

Transfer in

District $i$

$$
\tau_{D}^{* i}=\tau_{D}^{*-i}=\frac{1}{2} \quad \forall i
$$

$$
\begin{aligned}
& T_{D}^{* i} \\
& =\frac{1}{2} \int_{\underline{w}^{i}}^{\bar{w}^{i}} h^{i}\left(w^{i}\right) w^{i} d w^{i} \quad \forall i
\end{aligned}
$$

$$
B_{D}^{*}
$$

Designated for

Public

Redistribution

Share of Overall

Resources

Designated for

Redistribution in

District $i$

$$
=\frac{\sum_{\forall i=1,2} \int_{\underline{w}^{i}}^{\bar{w}^{i}} h^{i}\left(w^{i}\right) w^{i} d w^{i}}{2}
$$

$$
S_{D}^{* i}=\frac{T_{D}^{* i}}{B_{D}^{*}}
$$$$
=\frac{\int_{\underline{w}^{i}}^{\bar{w}^{i}} h^{i}\left(w^{i}\right) w^{i} d w^{i}}{\sum_{\forall i=1,2} \int_{\underline{w}^{i}}^{\bar{w}^{i}} h^{i}\left(w^{i}\right) w^{i} d w^{i}} \forall
$$

Share of Overall

Resources

Designated for

Redistribution in

District $i$

$$
\xi^{* i}=\frac{\int_{\underline{w}^{i}}^{\bar{w}^{i}} h^{i}\left(w^{i}\right) \Omega_{c}^{i} \alpha^{i} d w^{i}}{\sum_{\forall i=1,2} \int_{\underline{w}^{i}}^{\bar{w}^{i}} h^{i}\left(w^{i}\right) \Omega_{c}^{i} \alpha^{i} d w^{i}} \forall i
$$

Source: Own elaboration. 
Table 1

Equilibrium Conditions under Fiscal Decentralization and Tax Revenue Sharing

Case 2: With Spillovers

Policy Under Decentralization

Policy Under Tax Revenue Sharing

Tax Rate in District $i$

$$
\tau_{D}^{* i}=\tau_{D}^{*-i}=\frac{1}{2} \quad \forall i
$$

$$
\tau_{c}^{*}=\tau_{c}^{* i}=\tau_{c}^{*-i}=\frac{1}{2}
$$

$\tilde{T}_{c}^{* i}$

Per-Capita Transfer in District $i$

$$
T_{D}^{* i}=\frac{1}{2} \int_{\underline{w}^{i}}^{\bar{w}^{i}} h^{i}\left(w^{i}\right) w^{i} d w^{i} \quad \forall i
$$$$
=\frac{\tilde{\xi}^{* i}}{2} \sum_{\forall i=1,2} \int_{\underline{w}^{i}}^{\bar{w}^{i}} h^{i}\left(w^{i}\right) w^{i} d w^{i} \forall i
$$

Size of Resources

for Public

Redistribution

$$
B_{D}^{*}=\frac{\sum_{\forall i=1,2} \int_{\underline{w}^{i}}^{\bar{w}^{i}} h^{i}\left(w^{i}\right) w^{i} d w^{i}}{2} \quad=\frac{1}{2} \sum_{\forall i=1,2} \int_{\underline{w}^{i}}^{\bar{w}^{i}} h^{i}\left(w^{i}\right) w^{i} d w^{i} \forall i
$$

Share of Overall

Resources for

Redistribution in

District $i$

$$
=\frac{\int_{D}^{* i}}{\sum_{\forall i=1,2} \int_{\underline{w}^{i}}^{\bar{w}^{i}} h^{i}\left(w^{i}\right) w^{i} d w^{i}} \forall i
$$

Share of Overall

Resources for

Redistribution in

District $i$

$$
\begin{gathered}
\tilde{\xi}^{* i}=\frac{\Phi^{i}}{\Phi^{i}+\Phi^{-i}} \forall i \\
\Phi^{i}=\int_{\underline{w}^{i}}^{\bar{w}^{i}} h^{i}\left(w^{i}\right) \Omega_{c}^{i} \alpha^{i} d w^{i} \\
+k^{-i} \int_{\underline{w}^{-i}}^{\bar{w}^{-i}} h^{-i}\left(w^{-i}\right) \Omega_{c}^{-i} \alpha^{-i} d w^{-i} \forall i
\end{gathered}
$$

Source: Own elaboration. 
Table 2

Share of Resources Designated for Redistribution by State Under Decentralization and Tax Revenue Sharing. Case 1: No Spillovers

\begin{tabular}{|c|c|c|c|c|}
\hline State & $\begin{array}{c}\text { Descentralization } \\
\qquad T_{D}^{* i} / B_{D}^{*}\end{array}$ & $\begin{array}{c}\text { Tax } \\
\text { Revenue } \\
\text { Sharing } \\
\text { With Social } \\
\text { Weight } \\
\text { Inverse to } \\
\text { Per-Capita } \\
\text { Income }\end{array}$ & $\begin{array}{c}\text { Tax } \\
\text { Revenue } \\
\text { Sharing } \\
\text { With } \\
\text { Paretian } \\
\text { Distribution } \\
\text { Teta=1 }\end{array}$ & $\begin{array}{c}\text { Tax } \\
\text { Revenue } \\
\text { Sharing } \\
\text { With } \\
\text { Paretian } \\
\text { Distribution } \\
\text { Teta= } 2\end{array}$ \\
\hline & & $\boldsymbol{T}_{C}^{* i} / \boldsymbol{B}_{C}^{*}$ & $\boldsymbol{T}_{C}^{* i} / \boldsymbol{B}_{C}^{*}$ & $\boldsymbol{T}_{C}^{* i} / \boldsymbol{B}_{C}^{*}$ \\
\hline Chiapas & 1.30 & 6.50 & 11.88 & 19.32 \\
\hline Oaxaca & 1.61 & 5.25 & 7.74 & 10.17 \\
\hline Guerrero & 1.71 & 4.95 & 6.89 & 8.54 \\
\hline Tlaxcala & 1.80 & 4.69 & 6.19 & 7.27 \\
\hline Zacatecas & 1.89 & 4.48 & 5.63 & 6.31 \\
\hline Puebla & 2.06 & 4.12 & 4.76 & 4.90 \\
\hline Michoacán & 2.15 & 3.95 & 4.38 & 4.32 \\
\hline México & 2.30 & 3.69 & 3.82 & 3.52 \\
\hline Nayarit & 2.30 & 3.68 & 3.81 & 3.52 \\
\hline Tabasco & 2.38 & 3.56 & 3.55 & 3.16 \\
\hline Veracruz & 2.40 & 3.53 & 3.50 & 3.09 \\
\hline Hidalgo & 2.42 & 3.50 & 3.45 & 3.03 \\
\hline Morelos & 2.46 & 3.44 & 3.33 & 2.86 \\
\hline Durango & 2.74 & 3.09 & 2.68 & 2.07 \\
\hline San Luis Potosí & 2.75 & 3.08 & 2.67 & 2.06 \\
\hline Sinaloa & 2.86 & 2.97 & 2.47 & 1.83 \\
\hline Guanajuato & 2.93 & 2.89 & 2.35 & 1.70 \\
\hline Yucatán & 2.94 & 2.88 & 2.33 & 1.68 \\
\hline Chihuahua & 3.04 & 2.79 & 2.19 & 1.53 \\
\hline Tamaulipas & 3.21 & 2.64 & 1.95 & 1.29 \\
\hline Baja California & 3.31 & 2.56 & 1.84 & 1.17 \\
\hline Jalisco & 3.39 & 2.50 & 1.75 & 1.10 \\
\hline Colima & 3.46 & 2.45 & 1.68 & 1.03 \\
\hline Sonora & 3.62 & 2.34 & 1.54 & 0.90 \\
\hline Aguascalientes & 3.87 & 2.19 & 1.34 & 0.73 \\
\hline Baja California Sur & 4.06 & 2.09 & 1.22 & 0.64 \\
\hline Campeche & 4.27 & 1.98 & 1.10 & 0.55 \\
\hline Quintana Roo & 4.43 & 1.91 & 1.03 & 0.49 \\
\hline Querétaro & 4.50 & 1.88 & 1.00 & 0.47 \\
\hline Coahuila & 4.62 & 1.83 & 0.95 & 0.43 \\
\hline Nuevo León & 5.86 & 1.45 & 0.59 & 0.21 \\
\hline Ciudad de México & 7.36 & 1.15 & 0.37 & 0.11 \\
\hline
\end{tabular}


Table 3

Share of Resources Devoted for Redistribution by State under Decentralization and Tax Revenue Sharing Case 2: Spillovers

\begin{tabular}{|c|c|c|c|c|}
\hline State & $\begin{array}{c}\text { Descentralization } \\
\qquad T_{D}^{* i} / B_{D}^{*}\end{array}$ & $\begin{array}{c}\text { Revenue } \\
\text { Sharing With } \\
\text { Social Weight } \\
\text { Inverse to Per- } \\
\text { Capita Income } \\
\qquad T_{C}^{* i} / B_{C}^{*}\end{array}$ & $\begin{array}{c}\text { Tax } \\
\text { Revenue } \\
\text { Sharing } \\
\text { With } \\
\text { Paretian } \\
\text { Distribution } \\
\text { Teta=1 } \\
T_{C}^{* i} / B_{C}^{*}\end{array}$ & $\begin{array}{c}\text { Tax Revenue } \\
\text { Sharing With } \\
\text { Paretian } \\
\text { Distribution } \\
\text { Teta=2 } \\
T_{C}^{* i} / B_{C}^{*}\end{array}$ \\
\hline Chiapas & 1.30 & 4.73 & 7.24 & 10.65 \\
\hline Oaxaca & 1.61 & 4.15 & 5.33 & 6.43 \\
\hline Guerrero & 1.71 & 4.02 & 4.93 & 5.69 \\
\hline Tlaxcala & 1.80 & 3.94 & 4.66 & 5.16 \\
\hline Zacatecas & 1.89 & 3.82 & 4.38 & 4.68 \\
\hline Puebla & 2.06 & 3.57 & 3.86 & 3.92 \\
\hline Michoacán & 2.15 & 3.51 & 3.71 & 3.68 \\
\hline México & 2.30 & 3.21 & 3.26 & 3.14 \\
\hline Nayarit & 2.30 & 3.44 & 3.50 & 3.35 \\
\hline Tabasco & 2.38 & 3.36 & 3.35 & 3.17 \\
\hline Veracruz & 2.40 & 3.26 & 3.24 & 3.06 \\
\hline Hidalgo & 2.42 & 3.32 & 3.30 & 3.09 \\
\hline Morelos & 2.46 & 3.31 & 3.25 & 3.03 \\
\hline Durango & 2.74 & 3.14 & 2.94 & 2.65 \\
\hline San Luis Potosí & 2.75 & 3.12 & 2.92 & 2.64 \\
\hline Sinaloa & 2.86 & 3.06 & 2.82 & 2.53 \\
\hline Guanajuato & 2.93 & 2.99 & 2.74 & 2.45 \\
\hline Yucatán & 2.94 & 3.03 & 2.76 & 2.46 \\
\hline Chihuahua & 3.04 & 2.96 & 2.68 & 2.38 \\
\hline Tamaulipas & 3.21 & 2.89 & 2.57 & 2.27 \\
\hline Baja California & 3.31 & 2.85 & 2.51 & 2.21 \\
\hline Jalisco & 3.39 & 2.78 & 2.44 & 2.16 \\
\hline Colima & 3.46 & 2.83 & 2.46 & 2.16 \\
\hline Sonora & 3.62 & 2.75 & 2.37 & 2.09 \\
\hline Aguascalientes & 3.87 & 2.69 & 2.29 & 2.01 \\
\hline Baja California Sur & 4.06 & 2.65 & 2.23 & 1.97 \\
\hline Campeche & 4.27 & 2.59 & 2.18 & 1.92 \\
\hline Quintana Roo & 4.43 & 2.56 & 2.14 & 1.90 \\
\hline Querétaro & 4.50 & 2.54 & 2.12 & 1.88 \\
\hline Coahuila & 4.62 & 2.50 & 2.09 & 1.86 \\
\hline Nuevo León & 5.86 & 2.30 & 1.91 & 1.76 \\
\hline Ciudad de México & 7.36 & 2.14 & 1.80 & 1.71 \\
\hline
\end{tabular}


Table 4

Comparison of the Allocation of Resources Between Decentralization and Tax Revenue Sharing for the Cases With and Without Spillovers

Share of Overall Resources for Redistribution in District $i$

Case 1. No

Spillovers

\begin{tabular}{cccc}
\hline & Tax & Tax & Tax \\
& Revenue & Revenue & Revenue \\
Decentraliza & Sharing & Sharing & Sharing \\
tion & Social & Paretian & Paretian \\
& Weight & Distribution & Distribution
\end{tabular}

Three States with the

Lowest Per capita Inverse to Income Distribution

Teta $=1$

Distribution States with the

Highest Per Capita

17.84

4.43

1.90

0.75 Income

\section{Case 2:}

Spillovers

Three States with the

Lowest Per capita

4.63

12.90

17.50

22.77

Income

Three States with the

Highest Per Capita

17.84

6.95

5.81

5.33

Income

Source: Own elaboration. 